Article

\title{
Annual Performance of Sensible and Total Heat Recovery in Ventilation Systems: Humidity Control Constraints for European Climates
}

\author{
Stefanie Tafelmeier *, Giovanni Pernigotto and Andrea Gasparella \\ Faculty of Science and Technology, Free University of Bozen-Bolzano, piazza Università 5, 39100 Bolzano, Italy; \\ giovanni.pernigotto@unibz.it (G.P.); andrea.gasparella@unibz.it (A.G.) \\ * Correspondence: stefanie.tafelmeier@natec.unibz.it; Tel.: +39-0471-017663, Fax: +39-0471-017009 \\ Academic Editor: Alan Short \\ Received: 30 December 2016; Accepted: 21 March 2017; Published: 25 March 2017
}

\begin{abstract}
Ensuring a comfortable indoor air quality requires a minimum fresh air supply by ventilation. Moreover, the improvement of the air tightness in new and refurbished high performance buildings enhances the role of mechanical ventilation and its importance in further increasing the energy efficiency. Indeed, a reduction of the ventilation load can be achieved by installing air-to-air heat recovery devices, whose potential energy savings can be easily assessed by means of their nominal effectiveness. However, this estimation does not consider the impact on the overall performance of the system, in particular when humidity control is needed. Proper control strategies can be defined on the basis of the indoor latent load to prevent preheating or avoid moisture recovery when dehumidification by cooling is then required. In this work, the energy saving potential of heat recovery systems has been analyzed, considering the impact of different control strategies on both energy and cost savings. The calculations have been generalized using the specific latent load, which allows for the analysis of strategies and savings based on typical utilization categories, without considering in detail all the building characteristics. Representative hourly weather data for 66 European cities have been used to evaluate sensible and total heat recovery devices. The energy and the cost saving results have been mapped per each European Köppen-Geiger climate class and each country, respectively. The proposed strategies based on humidity control can strongly reduce the attractiveness of total heat recovery with respect to sensible heat recovery in terms of energy and cost savings, especially when high specific latent loads are considered.
\end{abstract}

Keywords: ventilation heat recovery; sensible heat recovery; total heat recovery; humidity control; energy savings; economic analysis

\section{Introduction}

Providing a sufficient amount of fresh air to the indoor environment is a crucial task for mechanical ventilation systems, especially in new or renovated high performance buildings with improved air tightness. Ventilation plays a major role in the energy consumption of a building. Its share and relevance increase with decreasing overall energy consumption. Nevertheless, with respect to natural ventilation, mechanical ventilation systems allow containment of the ventilation demand by deploying heat recovery devices.

Ventilation is relevant not only to the indoor air quality and the energy demand but also to the humidity control. While a high tolerance in the sensation of relative humidity is often reported by some field studies [1], some other works underline the influence of humidity on the performance of the occupants. Kosonen and Tan [2] and Tsutsumi et al. [3] indicated a negative correlation between the performance of a person and high relative humidity values. Chen et al. [4] reported occupants' 
complaints about fatigue aroused by low humidity. Moreover, Sterling et al. [5] underlined that excessive humidity can damage building and furniture materials and, in some cases, lead to health problems of the occupants.

For the above reasons, the control strategy of mechanical ventilation systems should account for the humidity as well as temperature. In particular, when dehumidification by cooling processes is needed, heat recovery can be counter effective, because of the subsequent need for cooling the fresh air to the dew point conditions. This effect can be emphasized by heat recovery systems able to recover latent and sensible heat, as shown by Smith and Svendsen [6], who investigated three different scenarios of moisture production and simulated the annual humidity level profile when heat recovery was used, disclosing occurrences of excessive humidity because of excessive recovery. Some studies in the literature also compared the performance of system configurations equipped with either sensible or latent heat recovery devices [7-9] or the impact of frost-protection methods on the energy recovery [10]. Furthermore, some researchers gave suggestions for retrofit requirements according to the different climate characteristics, as in [11].

This work investigates the impact of a humidity control strategy on the annual saving potential by Sensible and Total Heat Recovery (SHR and THR), considering different indoor humidity loads and outside air conditions. To do so, other than a baseline control strategy of recovering heat whenever temperature (for SHR) or enthalpy (for THR) gradients are favorable, an alternative control strategy is adopted to bypass the device whenever dehumidification by cooling of the outside air is necessary and heat recovery is counterproductive. Excessive humidity recovery by THR is avoided first by reducing the effectiveness and ultimately by excluding the heat exchanger. Furthermore, the impact of indoor vapor production related to the activity of occupants has been taken into account. The comparison between the saving potential with and without a humidity-based control strategy has been repeated for 66 cities in Europe. The performance has been calculated for each location starting from the corresponding reference year and averaged for all the locations belonging to the same Köppen-Geiger climate zone. This has allowed for geographically mapping the heat recovery energy and the economic performance.

\section{Methods}

\subsection{Air Handling Unit Configuration and Heat Recovery System}

A typical configuration has been considered for the Air Handling Unit $A H U$ (Figure 1), consisting of a set of heating/cooling and dehumidification, humidification, and reheating coils to achieve the required supply air $(S A)$ condition. The return air $(R A)$ of the space is separated into a recirculated $(C A)$ and an exhausted part $(E A)$. The latter one is used for preconditioning the outside air $(O A)$ within the heat recovery $(H R)$ device. After leaving the $H R$, the recovery air $(R)$ together with the $C A$ are mixed $(M A)$ and sent to the $A H U$ coils.

The change of the air condition through the HR is defined by the device sensible $\varepsilon_{s}$, latent $\varepsilon_{l}$, and enthalpy/total $\varepsilon_{t}$ effectiveness:

$$
\begin{gathered}
\varepsilon_{s}=\left(m_{O A} / m_{\min }\right) \times\left(T_{R}-T_{O A}\right) /\left(T_{R A}-T_{O A}\right) \\
\varepsilon_{l}=\left(m_{O A} / m_{\min }\right) \times\left(x_{R}-x_{O A}\right) /\left(x_{R A}-x_{O A}\right) \\
\varepsilon_{t}=\left(m_{O A} / m_{\min }\right) \times\left(h_{R}-h_{O A}\right) /\left(h_{R A}-h_{O A}\right)
\end{gathered}
$$

where $T$ is the temperature, $x$ is the humidity ratio and $h$ is the enthalpy, with the subscripts corresponding to the positions in Figure 1, and $m_{O A}$ and $m_{\min }$ are the outside and minimum air flow rates, respectively. The last value is typically in the range between $m_{O A}$ and $m_{E A}$. In this work, equal outside and exhausted air rates are considered, so that $m_{\min }$ is identical to $m_{O A}$. For THR devices, $\varepsilon_{s}, \varepsilon_{l}$, and consequently $\varepsilon_{t}$ are considered equal, while $\varepsilon_{l}$ for $S H R$ is zero by definition. 


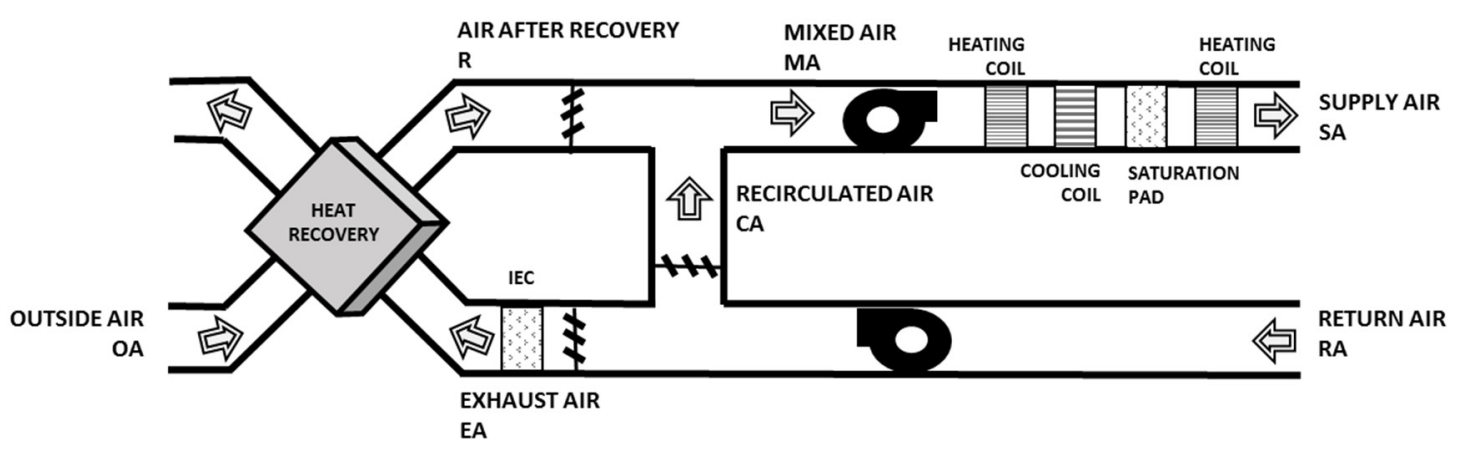

Figure 1. Ventilation and air conditioning cycle with heat recovery.

\subsection{Relative Humidity Control in Winter Mode}

Due to the low $O A$ humidity ratio in winter mode, $M A$ humidification is often required. Nevertheless, the $S A$ humidity ratio must be lowered to the room condition $(R A)$ setpoint to balance the internal latent load $m_{L}$. This can be expressed by the mass balance equation in steady state:

$$
x_{S A}=x_{R A}-m_{L} / m_{M A}
$$

For $x_{M A}$ lower or equal to $x_{S A}$, adiabatic humidification is a relatively energy inexpensive treatment to reach the supply condition. In contrast, if $x_{M A}$ is larger than $x_{S A}$, dehumidification is necessary, which is typically obtained by cooling the $M A$ to well below its dew point, at a high energy cost, and possibly wasting any previously recovered heat. It follows that the energy demand in winter mode is minimized when:

$$
x_{M A} \leq x_{S A}=x_{R A}-m_{L} / m_{M A}
$$

Considering a $H R$ device and the mixing process,

$$
x_{M A}=\left(x_{R} m_{O A}+x_{R A} m_{C A}\right) / m_{M A}
$$

this can be expressed as:

$$
x_{R} \leq x_{R A}-m_{L} / m_{O A}
$$

as described in detail in [12]. By this equation, the constraint on the $x_{R}$ can be described as a function of $x_{R A}$ and the latent load per unit of $O A$ flow rate. In the case of no recovery or $S H R, x_{R}$ is equal to $x_{O A}$ :

$$
x_{O A} \leq x_{R A}-m_{L} / m_{O A}
$$

The quantity

$$
\Delta x=m_{L} / m_{O A}
$$

In Equations (7) and (8) is the Specific Latent Load (SLL). Its value can be defined directly from the activity level of occupants within a conditioned space, without taking into account other building or occupation characteristics. Assuming for instance the values suggested by the technical standard ISO 7730 [13] (Table 1) for the latent load per person and the minimum fresh air rate per person as from the Italian national standard UNI 10339 [14], SLL can be determined for various activity levels. Five SLLs have been considered in this study to discriminate between typical rest or moderate activity levels: $0.8,1.2,1.6,2.0$, and $2.4 \mathrm{~g}_{\mathrm{v}} / \mathrm{kg}_{\mathrm{da}}$. 
Table 1. Thermal load gains depending on the activity and building type.

\begin{tabular}{|c|c|c|c|c|c|c|c|}
\hline \multirow[b]{2}{*}{ Activity } & \multirow[b]{2}{*}{ Type of Building } & \multicolumn{4}{|c|}{ Thermal Load per Person ${ }^{(1)}$} & \multirow{2}{*}{$\begin{array}{l}\text { Air Change }{ }^{(2)} \\
{[1 /(\text { s person })]}\end{array}$} & \multirow{2}{*}{$\begin{array}{c}\text { Sensible Latent } \\
\text { Load (SLL) } \\
{\left[\mathrm{g}_{\mathrm{v}} / \mathrm{kg}_{\mathrm{da}}\right]}\end{array}$} \\
\hline & & $\begin{array}{l}\text { Total Load } \\
{[\mathrm{W}]}\end{array}$ & $\begin{array}{l}\text { Sensible } \\
\text { Load [W] }\end{array}$ & $\begin{array}{c}\text { Latent Load } \\
{[W]}\end{array}$ & $\begin{array}{c}\text { Latent Load } \\
{\left[\mathrm{g}_{\mathrm{v}} / \mathrm{h}\right]}\end{array}$ & & \\
\hline Seated, relaxed & Theatre, Cinema & 100 & 60 & 40 & 57.6 & 5.5 & 2.4 \\
\hline Seated, writing & Offices, Hotel, Apartments & 120 & 65 & 55 & 79.2 & 11.0 & 1.7 \\
\hline Eating & Restaurants & 170 & 75 & 95 & 136.7 & 10.0 & 3.2 \\
\hline Seated, light activity, typing & Offices, Hotel, Apartments & 150 & 75 & 75 & 108.0 & 11.0 & 2.3 \\
\hline Slowly walking & Retail store, Bank & 185 & 90 & 95 & 136.7 & 11.5 & 2.8 \\
\hline Moderate dancing & Dance Hall & 375 & 120 & 255 & 367.1 & 16.5 & 5.1 \\
\hline
\end{tabular}

(1) ISO 7730; (2) UNI 10339. 


\subsection{Heat Recovery Limitation in Winter Mode}

In winter mode, operation heat recovery on the exhausted air is typically assumed to be beneficial whenever the room conditions (temperature for SHR and enthalpy for THR) are above the outdoor conditions (temperature and enthalpy, respectively). However, if the $O A$ humidity overcomes that limitation (8), dehumidification is necessary and $S H R$ is counterproductive. In order to avoid that, the control strategy is to bypass the SHR when (8) is not verified.

In the case of THR, the limitation in the expression (7) occurs. $x_{R}$ depends on the outside air, the exhaust air, and the effectiveness of the device. Different to the case of $S H R$, critical conditions can be prevented by properly reducing the latent (and total) heat recovery. This can be obtained through partial bypass or rotational speed modification in the case of rotary heat exchangers. The latent effectiveness, and correspondingly the total one, has to be limited to the operative value $\varepsilon_{l, o p}$ :

$$
\varepsilon_{l, o p} \leq \min \left[\varepsilon_{l} ; 1-\Delta x /\left(x_{R A}-x_{O A}\right)\right]
$$

It follows that $\varepsilon_{l, o p}$ is limited to a maximum ranging from $1-\Delta x / x_{R A}$ (or $\varepsilon_{l}$ if this is lower) to zero, while $x_{O A}$ goes from zero to $x_{R A}-\Delta x$. In other words, the operative effectiveness $\varepsilon_{l, o p}$ must be zero for $x_{O A}=x_{R A}-\Delta x$ and reaches its nominal value $\varepsilon_{l}$ when $x_{O A}=x_{R A}-\Delta x /\left(1-\varepsilon_{l}\right)$.

Summarizing, the investigation includes the calculation of the energy savings by SHR and THR, respectively, without (strategy or case A) or with control (strategy or case B) to maintain the indoor humidity at $50 \%$.

\subsection{Heat Recovery Limitation in Summer Mode}

In summer mode operation, heat recovery is generally assumed to be beneficial whenever the $R A$ temperature (in SHR) or enthalpy (in THR) are lower than the external ones, since the $O A$ conditions typically require air dehumidification by cooling. However, in some cases $x_{O A}$ is below $x_{S A}$, so that sensible cooling only is sufficient. In that case, whereas the pre-cooling by $S H R$ is always beneficial, the humidity recovery by THR can lead to an excessive humidification if Equation (8) is not verified. Applying the same $\varepsilon_{l}$ control in (10) avoids the dehumidification.

In addition, since SHR allows for indirect evaporative cooling (IEC) of the EA [15] before entering the device (Figure 1), the reference cases considered in summer mode operation are: $S H R+I E C$, and THR with no control strategy (case A) and with control strategy to avoid excessive humidification and maintain the indoor relative humidity at $50 \%$ (case B).

\subsection{Seasonal Energy and Annual Economic Performance}

The energy and cost savings on the ventilation load by SHR and THR are compared for cases A and $\mathrm{B}$. The results for case $\mathrm{A}$ are indicated also as the nominal performance or theoretical potential of $S H R$ and THR, assuming no limitation by the control. Full or nominal effectiveness recovery is considered for the winter mode whenever $T_{O A}<T_{R A}\left(20^{\circ} \mathrm{C}\right)$ for $S H R$, or $h_{O A}<h_{R A}(38.6 \mathrm{~kJ} / \mathrm{kg}$, i.e., $20{ }^{\circ} \mathrm{C}$ and $50 \%$ relative humidity) for THR. The same holds for summer with $T_{O A}>T_{R A}\left(26^{\circ} \mathrm{C}\right)$ and $h_{O A}>h_{R A}\left(52.91 \mathrm{~kJ} / \mathrm{kg}\right.$, i.e., $26{ }^{\circ} \mathrm{C}$ and $50 \%$ relative humidity) for $S H R$ and $T H R$, respectively.

The results for case $\mathrm{B}$ consider complete bypass of the heat exchanger whenever the outside humidity ratio overcomes the limit value expressed by (7) for SHR (white area in Figure 2) in winter mode operation, or reduced operation between $x_{O A}=x_{R A}-\Delta x /\left(1-\varepsilon_{l}\right)$ and $x_{R A}-\Delta x$ for THR (orange area in Figure 3) in both winter and summer.

The calculations are based on representative hourly weather data years of relative humidity and temperature provided by the EnergyPlus data base [16], for 66 cities in the 9 main different European climate classes (Table 2 and Figure 4). The cold climates are represented by the class Dsb that has a dry and warm summer and the classes Dfa, Dfb, and Dfc, which are without a dry season, but a hot, warm, and cold summer, respectively. The temperate climate classes are Csa and Csb that are with a dry and hot and dry and warm summer, respectively, as well as $\mathrm{Cfa}$ and $\mathrm{Cfb}$, which are without a 
dry season, but a hot and warm summer, respectively. The arid climate considered was BSk described as being steppe and cold [17]. The savings determined for each city in the same Köppen-Geiger climate zone have been averaged and mapped by a Geographic Information System (GIS) called QGIS (version 2.16.2). A Köppen-Geiger GIS climate map has been developed by ORNL DAAC (Oak Ridge National Laboratory Distributed Active Archive Center), one of the NASA Earth Observing System Data and Information System (EOSDIS) data centers.

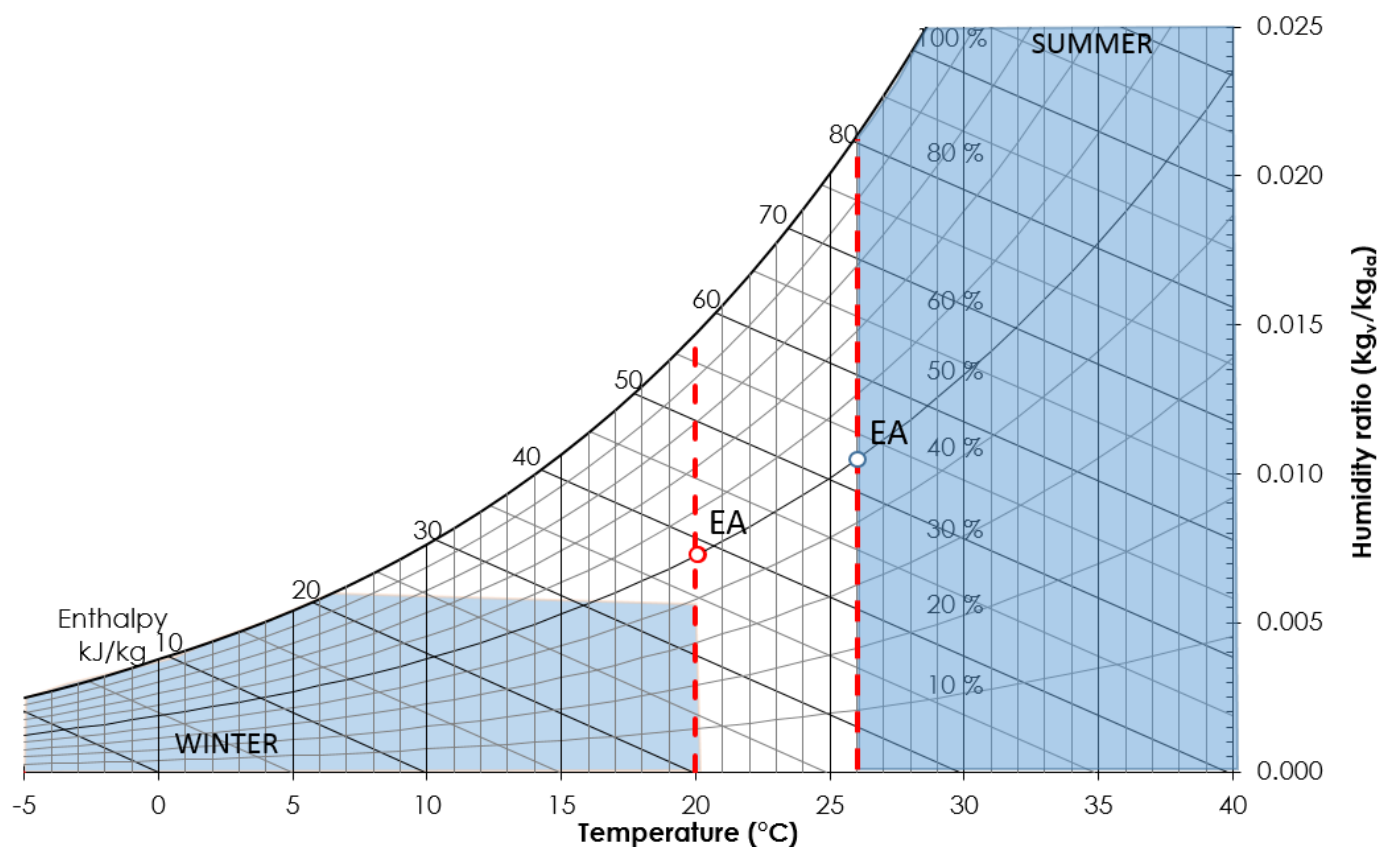

Figure 2. Psychrometric chart indicating winter and summer mode reference temperatures for sensible heat recovery $(S H R)$ of case A and operative areas of case B conditions: blue = nominal $\varepsilon_{S}$; white (below winter $T_{E A}$ ) = by-pass.

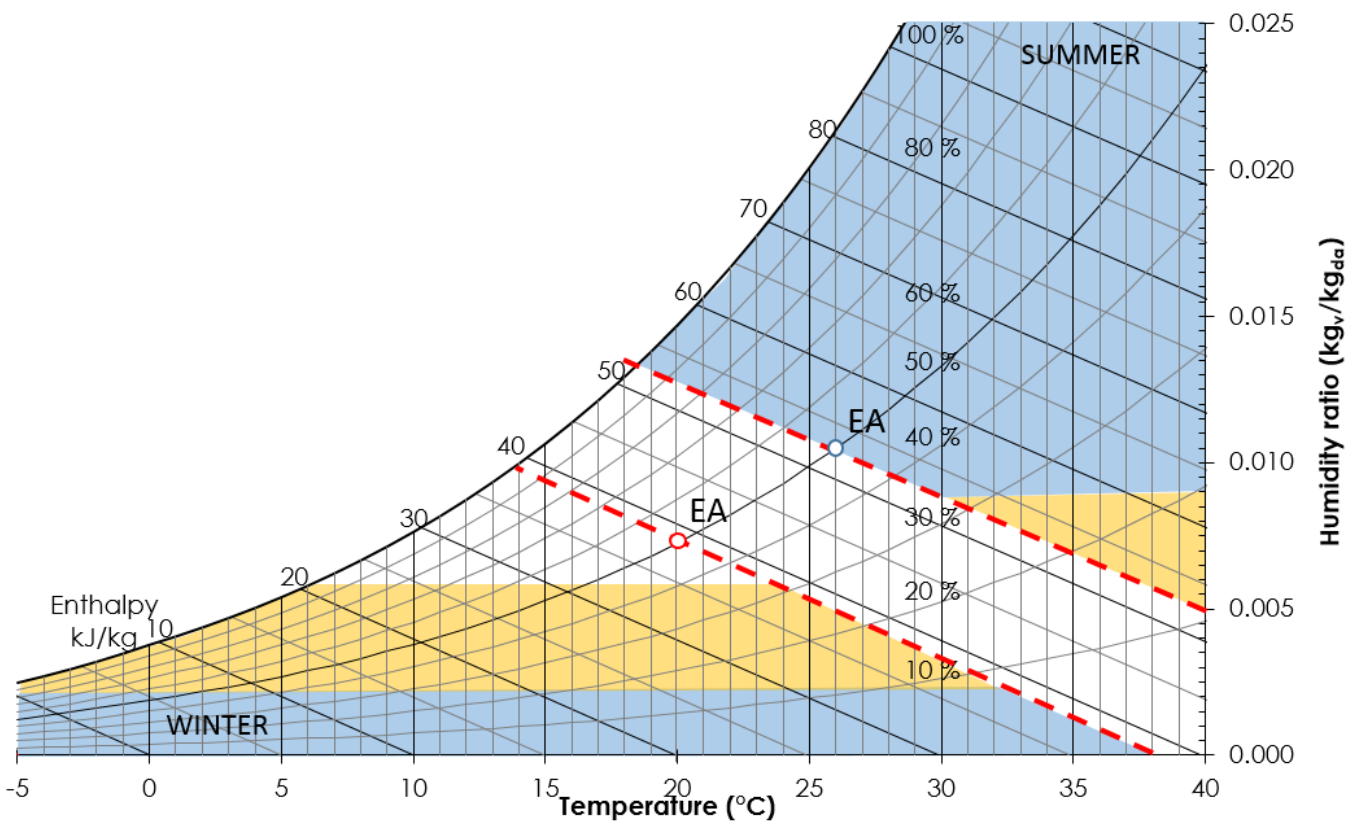

Figure 3. Psychrometric chart indicating winter and summer mode reference enthalpies for total heat recovery $(T H R)$ of case $\mathrm{A}$ and areas of case $\mathrm{B}$ conditions: blue $=$ nominal $\varepsilon_{l}$, orange $=$ controlled $\varepsilon_{l o p}$; white (below winter $h_{E A}$ ) = by-pass. 
Table 2. Example cities with their average annual temperature and relative humidity inclusive standard deviation and Köppen-Geiger climate classification.

\begin{tabular}{|c|c|c|c|c|c|}
\hline $\mathbf{N}$ & City & Country and Symbol & $T_{\text {avg }}\left[{ }^{\circ} \mathrm{C}\right]$ & $R H_{\text {avg }}[\%]$ & Köppen-Geiger Class \\
\hline 1 & Aberdeen & U.K. (UK) & $8.4 \pm 5.0$ & 79.812 .3 & $\mathrm{Cfb}$ \\
\hline 2 & Amsterdam & The Netherlands (NLD) & $10.0 \pm 6.2$ & $83.5 \pm 13.5$ & $\mathrm{Cfb}$ \\
\hline 3 & Andravida & Greece (GR) & $16.7 \pm 6.8$ & $74.1 \pm 17.4$ & Csa \\
\hline 4 & Ankara & Turkey (TR) & $9.6 \pm 9.7$ & $63.7 \pm 19.7$ & Dsb \\
\hline 5 & Arkhangelsk & Russia (RU) & $1.6 \pm 11.3$ & $79.7 \pm 14.8$ & Dfc \\
\hline 6 & Athens & Greece (GR) & $17.9 \pm 7.3$ & $61.5 \pm 15.5$ & Csa \\
\hline 7 & Barcelona & Spain (E) & $15.7 \pm 6.4$ & $74.0 \pm 14.8$ & Csa \\
\hline 8 & Bari & Italy (I) & $16.0 \pm 6.9$ & $69.6 \pm 14.6$ & Csa \\
\hline 9 & Belgrade & Serbia (RS) & $11.5 \pm 9.5$ & $76.1 \pm 17.7$ & Dfa \\
\hline 10 & Bergen & Norway (N) & $7.1 \pm 5.6$ & $79.7 \pm 17.6$ & $\mathrm{Cfb}$ \\
\hline 11 & Berlin & Germany (D) & $9.8 \pm 7.8$ & $73.5 \pm 17.1$ & $\mathrm{Cfb}$ \\
\hline 12 & Bilbao & Spain (E) & $14.1 \pm 5.5$ & $72.5 \pm 14.3$ & $\mathrm{Cfb}$ \\
\hline 13 & Birmingham & U.K. (UK) & $9.7 \pm 5.8$ & $78.4 \pm 15.3$ & $\mathrm{Cfb}$ \\
\hline 14 & Bologna & Italy (I) & $13.0 \pm 9.1$ & $78.2 \pm 18.9$ & $\mathrm{Cfa}$ \\
\hline 15 & Bordeaux & France (F) & $13.2 \pm 7.0$ & $76.4 \pm 17.6$ & $\mathrm{Cfb}$ \\
\hline 16 & Bucharest & Romania (RO) & $10.8 \pm 10.1$ & $77.2 \pm 21.4$ & Dfa \\
\hline 17 & Clermont-Ferrand & France (F) & $11.4 \pm 7.9$ & $72.3 \pm 18.1$ & $\mathrm{Cfb}$ \\
\hline 18 & Copenhagen & Denmark (DK) & $8.3 \pm 6.6$ & $77.4 \pm 14.4$ & $\mathrm{Cfb}$ \\
\hline 19 & Faro & Portugal (P) & $17.8 \pm 5.3$ & $72.3 \pm 16.3$ & Csa \\
\hline 20 & Finningley & U.K. (UK) & $9.5 \pm 5.8$ & $77.8 \pm 15.6$ & $\mathrm{Cfb}$ \\
\hline 21 & Frankfurt am Main & Germany (D) & $10.1 \pm 7.7$ & $75.8 \pm 17.0$ & $\mathrm{Cfb}$ \\
\hline 22 & Goteborg & Sweden (S) & $6.5 \pm 7.2$ & $79.9 \pm 17.3$ & Dfb \\
\hline 23 & Granada & Spain $(E)$ & $14.9 \pm 8.3$ & $59.7 \pm 22.9$ & Csa \\
\hline 24 & Hamburg & Germany (D) & $9.0 \pm 7.2$ & $79.6 \pm 14.8$ & $\mathrm{Cfb}$ \\
\hline 25 & Helsinki & Finland (FIN) & $5.2 \pm 8.8$ & $79.2 \pm 17.1$ & Dfb \\
\hline 26 & Istanbul & Turkey (TR) & $14.5 \pm 7.7$ & $72.2 \pm 14.7$ & Csa \\
\hline 27 & Kiev & Ukraine (UA) & $8.0 \pm 9.6$ & $76.3 \pm 17.2$ & Dfb \\
\hline 28 & Kiruna & Sweden (S) & $-1.1 \pm 10.1$ & $75.5 \pm 14.4$ & Dfc \\
\hline 29 & Krakow & Poland (PL) & $8.2 \pm 8.7$ & $77.1 \pm 15.7$ & Dfb \\
\hline 30 & La Coruna & Spain (E) & $14.1 \pm 4.1$ & $77.6 \pm 10.8$ & $\mathrm{Csb}$ \\
\hline 31 & Larnaca & Cyprus (CY) & $19.4 \pm 6.8$ & $68.6 \pm 15.3$ & Csa \\
\hline 32 & Leon & Spain (E) & $10.8 \pm 7.3$ & $65.3 \pm 19.6$ & $\mathrm{Csb}$ \\
\hline 33 & Lisbon & Portugal (P) & $16.3 \pm 5.8$ & $74.1 \pm 15.5$ & Csa \\
\hline 34 & London & U.K. (UK) & $10.2 \pm 6.1$ & $79.3 \pm 15.4$ & $\mathrm{Cfb}$ \\
\hline 35 & Madrid & Spain (E) & $14.3 \pm 8.6$ & $61.6 \pm 21.5$ & BSk \\
\hline 36 & Marseille & France (F) & $14.8 \pm 7.4$ & $69.2 \pm 17.1$ & Csa \\
\hline 37 & Messina & Italy (I) & $18.9 \pm 5.9$ & $71.7 \pm 14.3$ & Csa \\
\hline 38 & Milan & Italy (I) & $11.8 \pm 8.9$ & $75.1 \pm 19.7$ & $\mathrm{Cfa}$ \\
\hline 39 & Minsk & Belarus (BY) & $6.3 \pm 9.4$ & $77.2 \pm 17.3$ & Dfb \\
\hline 40 & Montpellier & France $(\mathrm{F})$ & $14.8 \pm 7.4$ & $68.7 \pm 20.2$ & Csa \\
\hline 41 & Moscow & Russia (RU) & $5.5 \pm 10.8$ & $77.3 \pm 16.0$ & Dfb \\
\hline 42 & Munich & Germany (D) & $8.0 \pm 8.4$ & $78.7 \pm 17.3$ & Dfb \\
\hline 43 & Nantes & France $(\mathrm{F})$ & $12.2 \pm 6.4$ & $79.2 \pm 17.1$ & $\mathrm{Cfb}$ \\
\hline 44 & Odessa & Ukraine (UA) & $10.1 \pm 9.8$ & $74.0 \pm 17.9$ & Dfa \\
\hline 45 & Oslo & Norway (N) & $6.7 \pm 8.3$ & $74.1 \pm 20.8$ & Dfb \\
\hline 46 & Ostersund & Sweden (S) & $3.2 \pm 8.3$ & $74.9 \pm 15.1$ & Dfc \\
\hline 47 & Ostrava & Czech Republic (CZ) & $8.5 \pm 8.5$ & $76.1 \pm 16.9$ & $\mathrm{Dfb}$ \\
\hline 48 & Paris & France (F) & $11.2 \pm 6.9$ & $76.9 \pm 16.6$ & $\mathrm{Cfb}$ \\
\hline 49 & Pescara & Italy (I) & $14.3 \pm 7.4$ & $77.5 \pm 17.7$ & $\mathrm{Cfa}$ \\
\hline 50 & Porto & Portugal (P) & $14.3 \pm 4.9$ & $79.0 \pm 15.3$ & $\mathrm{Csb}$ \\
\hline 51 & Poznan & Poland (PL) & $8.6 \pm 8.3$ & $78.1 \pm 16.7$ & Dfb \\
\hline 52 & Prague & Czech Republic (CZ) & $8.1 \pm 8.5$ & $76.7 \pm 16.6$ & Dfb \\
\hline 53 & Reykjavik & Iceland (IS) & $4.5 \pm 5.1$ & $77.2 \pm 13.3$ & Dfc \\
\hline 54 & Rome & Italy (I) & $15.8 \pm 6.9$ & $77.7 \pm 15.1$ & Csa \\
\hline 55 & Saint Petersburg & Russia (RU) & $5.4 \pm 9.4$ & $77.8 \pm 15.5$ & Dfb \\
\hline 56 & Sevilla & Spain (E) & $18.4 \pm 7.9$ & $62.6 \pm 22.2$ & Csa \\
\hline 57 & Sofia & Bulgaria (BG) & $10.2 \pm 8.8$ & $72.9 \pm 17.2$ & Dfb \\
\hline 58 & Stockholm & Sweden (S) & $6.5 \pm 8.3$ & $78.4 \pm 18.6$ & Dfb \\
\hline 59 & Strasbourg & France $(\mathrm{F})$ & $10.3 \pm 7.7$ & $79.1 \pm 16.1$ & $\mathrm{Cfb}$ \\
\hline 60 & Tampere & Finland (FIN) & $4.3 \pm 9.3$ & $79.1 \pm 17.6$ & Dfc \\
\hline 61 & Teruel & Spain (E) & $11.6 \pm 7.9$ & $61.4 \pm 20.0$ & BSk \\
\hline 62 & Thessaloniki & Greece (GR) & $15.4 \pm 8.1$ & $66.1 \pm 18.4$ & Csa \\
\hline 63 & Venice & Italy (I) & $13.2 \pm 8.2$ & $76.9 \pm 15.6$ & $\mathrm{Cfa}$ \\
\hline 64 & Vienna & Austria (AT) & $10.0 \pm 8.8$ & $71.7 \pm 16.9$ & Dfb \\
\hline 65 & Warsaw & Poland (PL) & $8.4 \pm 8.4$ & $79.6 \pm 15.7$ & Dfb \\
\hline 66 & Zaragoza & Spain (E) & $14.7 \pm 7.7$ & $62.8 \pm 19.4$ & BSk \\
\hline
\end{tabular}




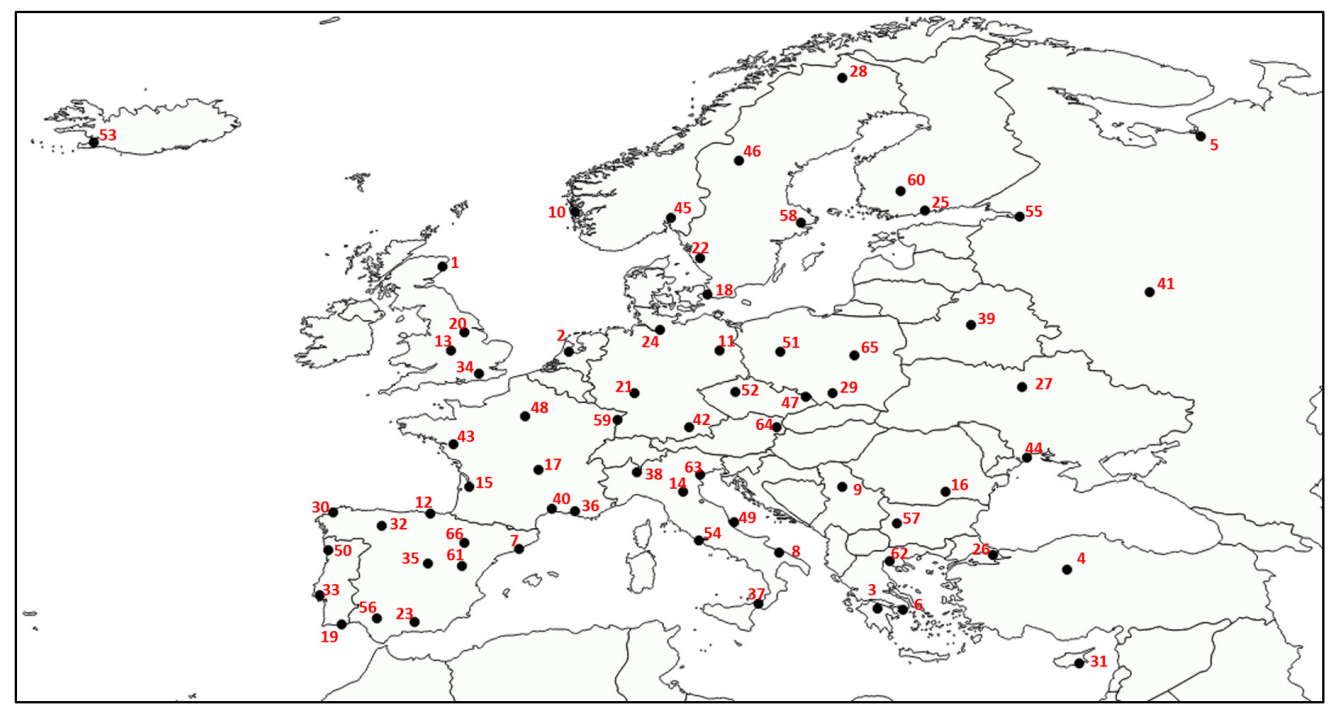

Figure 4. Map of Europe with the 66 considered cities. Numbers correspond to Table 2.

The analysis is based on the following assumptions:

- A nominal value of $70 \%$ has been assumed for both sensible and total effectiveness in SHR and THR calculations, considering latent effectiveness equal to total for the latter. This value has been chosen because, although there is no European recommendation for the minimum effectiveness for heat recovery devices for mechanical ventilation, many countries, such as Italy, Sweden, or Denmark, ask for or recommend a nominal effectiveness of at least $70 \%$ [18].

Influences of air temperature, flow rate, and condensation on the effectiveness have not been considered as they strongly depend on the device specific technology [8,19-22]. Some of those aspects have been discussed for SHR in a previous work [23], according to a simplified approach based on the experimental results by Nam and Han [24]: the largest variation of sensible effectiveness has been found for the city of Helsinki (Dfb) and is equal to $+4 \%$ with respect to the nominal effectiveness at the $E A$ condition of $20{ }^{\circ} \mathrm{C}$ and $60 \%$ relative humidity. Since the impact has been found to be small, in order to keep the analysis independent of the $H R$ device, such variations have not been considered.

- The seasonal efficiency of the natural gas boiler for hot water supply to $A H U$ heating coils has been assumed to be $80 \%$, the adiabatic humidification effectiveness in IEC equal to 0.9 , and the $\mathrm{COP}$ of the refrigeration cycle supplying the cooling coils calculated as $30 \%$ of an ideal Carnot's COP operating between $10^{\circ} \mathrm{C}$ and the $T_{O A}$.

- Natural gas and electricity prices have been taken from the European Union Eurostat [25], except for natural gas prices in Finland and Norway. Table 3 reports the prices for the main countries, i.e., those for which the number of analyzed climates have been considered appropriate for the calculation of national averages of cost savings and economic indexes. For other localities, calculations have been made but the national average has not been reported. Furthermore, due to lack of complete price information, localities in Belarus, Cyprus, Iceland, Russia, and Ukraine have been excluded from economic analysis.

- In order to calculate the economic performance indicators, i.e., simple payback time and net present value, the investment cost per flow rate has been determined based on the price list for the performance of public works and maintenance of the municipality of Milan [26] as $0.7 \mathrm{EUR} /(\mathrm{l} / \mathrm{s})$ for $S H R$ and $2.3 \mathrm{EUR} /(1 / \mathrm{s})$ for THR. The calculation of the net present value assumed, according to the EU Commission Delegated Regulation 244/2012 [27], a lifespan of 15 years, a real discount rate of $3 \%$, and annual maintenance costs of $4 \%$ of the investment. 
- Energy and non-energy cost (such as pressure losses) items not involving differences between SHR and THR or between different control strategies have been neglected, as well as additional savings by the possibility of downscaling of the air treatment devices in case of heat recovery use.

The energy savings in winter mode have been determined as recovered enthalpy starting from the outside air conditions and are expressed per unit of $O A$ flow rate, i.e., in kilowatt-hour per liter per second. On the contrary, energy savings in summer mode have been estimated in terms of specific electrical savings, in terms of electrical kilowatt-hour per liter per second. In that way, the results can be easily generalized to different buildings sizes.

For $S L L=1.6 \mathrm{~g}_{\mathrm{v}} / \mathrm{kg}_{\mathrm{da}}$, further analyses have been performed in order to discuss more in detail the extent of the representativeness of the findings: specifically, a sensitivity analysis on the nominal effectiveness, the impact of frost protection strategies, and the hourly distribution of energy savings have been investigated and discussed.

Table 3. Price for electricity [EUR/kWh $\mathrm{el}_{\mathrm{e}}$ and natural gas [EUR/kWh] for the main countries.

\begin{tabular}{|c|c|c|c|c|c|c|c|c|c|c|c|c|c|}
\hline State & $\mathrm{CZ}$ & D & E & F & FIN & GR & I & $\mathbf{N}$ & NLD & $\mathbf{P}$ & PL & $S$ & UK \\
\hline electricity cost & 0.13 & 0.30 & 0.24 & 0.17 & 0.15 & 0.18 & 0.24 & 0.14 & 0.18 & 0.23 & 0.14 & 0.19 & 0.22 \\
\hline natural gas cost & 0.058 & 0.068 & 0.093 & 0.073 & $0.040 *$ & 0.075 & 0.091 & $0.07^{* *}$ & 0.077 & 0.098 & 0.050 & 0.12 & 0.071 \\
\hline
\end{tabular}

\section{Results and Discussion}

\subsection{Sensible Heat Recovery}

Considering the winter mode, as can be seen from the map (Figure 5), the largest savings for case A can be achieved for the climatic zone Dfc, most of Scandinavia, and Iceland, while the lowest is for the Mediterranean regions, especially for zone Csa. In particular, Kiruna, northern Sweden, shows the highest saving potential of $195.9 \mathrm{kWh} /(1 / \mathrm{s})$, while the worst saving potential is for Messina in Sicily, Italy, with $29.6 \mathrm{kWh} /(1 / \mathrm{s})$. Sorted by increasing values, the energy savings are 47.4 (with a spread, i.e., the difference between maximum and minimum values for the climatic region, of 32.8), 67.3 (spread: 34.4), 71.5 (spread: 24.1), 74 (spread: 21.6), 93.3 (spread: 60.7), 94.1 (spread: 10.6), 103.7, 118.7 (spread: 42.7) and 163.2 (spread: 51.8$) \mathrm{kWh} /(\mathrm{l} / \mathrm{s}$ ), respectively, for Csa, Csb, BSk, Cfa, Cfb, Dfa, $\mathrm{Dsb}, \mathrm{Dfb}$, and Dfc. The most representative cities are, respectively, Bari, La Coruna, Madrid, Venice, London, Bucharest, Ankara, Kiev, and Ostersund. Among these zones, a minimum standard deviation is observed for the zone Dfa (i.e., 5.7\%), and the largest for Csb (i.e., 29.3\%).

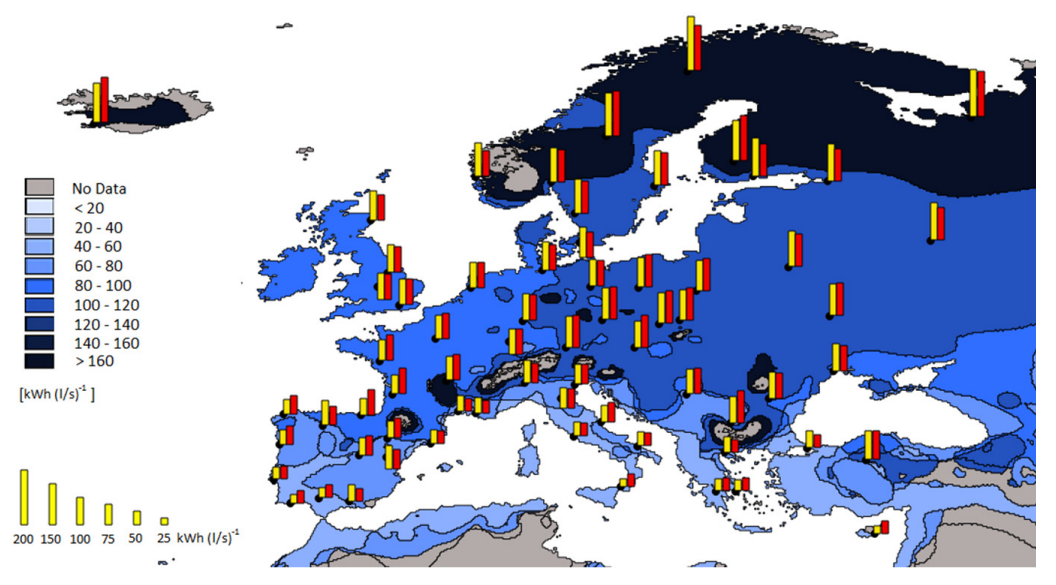

Figure 5. Heating energy savings on the ventilation load for the SHR control strategy A. Colours and red bars indicate the average in the climatic zone. Yellow bar indicates the performance of each locality. 
By applying the control strategy B, the maximum percentage reduction of energy savings occurs for Csa, whereas for Dfc the impact is marginal (Figure 6). The range of the reduction of the savings (Table 4) is from $5.3 \%$ to $34.4 \%$ for $S S L=0.8 \mathrm{~g}_{\mathrm{v}} / \mathrm{kg}_{\mathrm{da}}$, from $7 \%$ to $42 \%$ for $S S L=1.2 \mathrm{~g} / \mathrm{gg}_{\mathrm{da}}$, from $9.3 \%$ to $49.7 \%$ for $S S L=1.6 \mathrm{~g}_{\mathrm{v}} / \mathrm{kg}_{\mathrm{da}}$, from $12 \%$ to $57.4 \%$ with $S S L=2 \mathrm{~g}_{\mathrm{v}} / \mathrm{kg}_{\mathrm{da}}$, and $15.2 \%$ to $65.3 \%$ for $S S L=2.4 \mathrm{~g}_{\mathrm{v}} / \mathrm{kg}_{\mathrm{da}}$. Among the considered cities, Kiruna (Dfc) still shows the highest saving potential, while Messina (Csa) and Lisbon, Faro, and La Coruna ( $\mathrm{Csb}$ ) have the minimum savings.

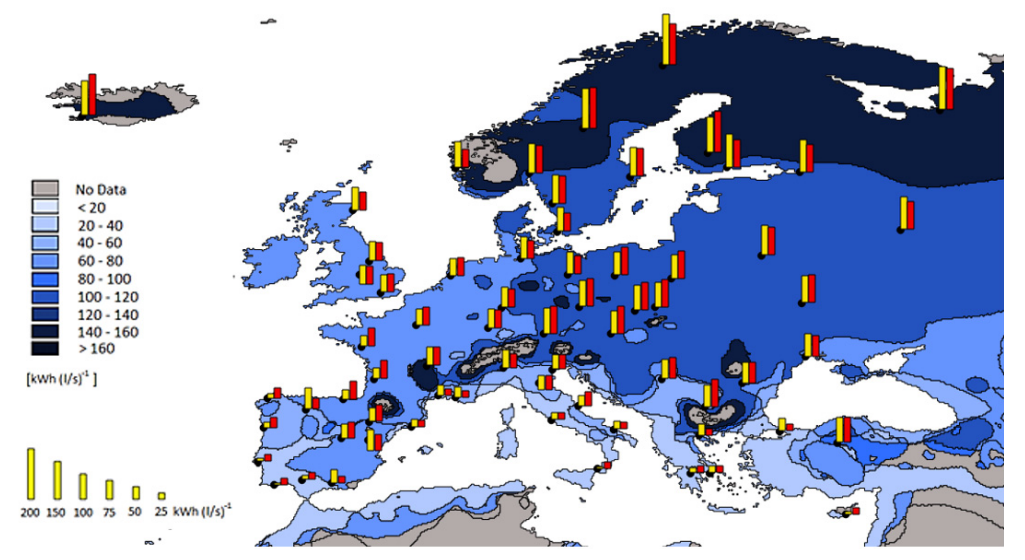

Figure 6. Heating energy savings on the ventilation load for the SHR control strategy B and $S L L=1.6 \mathrm{~g}_{\mathrm{v}} / \mathrm{kg}_{\mathrm{da}}$. Colours and red bars indicate the average in the climatic zone. Yellow bar indicates the performance of each locality.

Table 4. SHR absolute savings $[\mathrm{kWh} /(1 / \mathrm{s})]$ and percentage reduction in winter mode with respect to the potential for the control strategy $\mathrm{B}$.

\begin{tabular}{|c|c|c|c|c|c|c|c|c|c|c|}
\hline \multirow{2}{*}{$\begin{array}{l}\text { Climate } \\
\text { Class }\end{array}$} & \multicolumn{2}{|c|}{$0.8 \mathrm{~g}_{\mathrm{v}} / \mathrm{kg}_{\mathrm{da}}$} & \multicolumn{2}{|c|}{$1.2 \mathrm{~g}_{\mathrm{v}} / \mathrm{kg}_{\mathrm{da}}$} & \multicolumn{2}{|c|}{$1.6 \mathrm{~g}_{\mathrm{v}} / \mathrm{kg}_{\mathrm{da}}$} & \multicolumn{2}{|c|}{$2.0 \mathrm{~g}_{\mathrm{v}} / \mathrm{kg}_{\mathrm{da}}$} & \multicolumn{2}{|c|}{$2.4 \mathrm{~g}_{\mathrm{v}} / \mathrm{kg}_{\mathrm{da}}$} \\
\hline & $\Delta$ & $\Delta \%$ & $\Delta$ & $\Delta \%$ & $\Delta$ & $\Delta \%$ & $\Delta$ & $\Delta \%$ & $\Delta$ & $\Delta \%$ \\
\hline Csa & 16. & 34.4 & 19.9 & -42. & 23.5 & -49.7 & -27.2 & -57 & -30.9 & $-65.3 \%$ \\
\hline Csb & -22 & -3 & 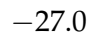 & -3 & -32.4 & $=$ & .8 & -55 & -41.9 & \\
\hline BSk & -7.8 & -11 & -10.4 & -14 & -14.0 & -1 & -20.0 & -28 & -26.0 & $-36.4 \%$ \\
\hline Cfa & -16.3 & $-22.0 \%$ & -19.4 & -26 & -22.9 & $-30.9 \%$ & -26.7 & $-36.1 \%$ & -32.0 & $-43.2 \%$ \\
\hline $\mathrm{Cfb}$ & -19.2 & $-20.6 \%$ & -23.7 & -25 & -29.3 & -31 & -35.7 & -38 & -43.0 & $-46.1 \%$ \\
\hline Dfa & -12.5 & $-13.3 \%$ & -14.7 & $-15.6 \%$ & -18.5 & $-19.6 \%$ & -22.2 & $-23.6 \%$ & -26.9 & $-28.6 \%$ \\
\hline Dsb & -6.8 & $-6.6 \%$ & -9.7 & $-9.3 \%$ & -12.4 & $-12.0 \%$ & -15.5 & $-15.0 \%$ & -19.3 & $-18.6 \%$ \\
\hline Dfb & -13.5 & $-11.4 \%$ & -16.4 & $-13.8 \%$ & -19.9 & $-16.7 \%$ & -23.6 & $-19.9 \%$ & -28.3 & $-23.8 \%$ \\
\hline Dfc & -8.7 & $-5.3 \%$ & -11.4 & $-7.0 \%$ & -15.1 & $-9.3 \%$ & -19.6 & $-12.0 \%$ & -24.9 & $-15.2 \%$ \\
\hline
\end{tabular}

In contrast to the winter mode, in summer mode, the SHR combined with IEC of the exhaust air yields the highest electrical savings in zone Csa and nearly negligible ones in zone Dfc (Table 5).

Table 5. SHR average savings in electrical energy demand in summer mode $\left[\mathrm{kWh}_{\mathrm{el}} /(\mathrm{l} / \mathrm{s})\right]$.

\begin{tabular}{cccccccccc}
\hline Electrical Energy Savings & Csa & Csb & BSk & Cfa & Cfb & Dfa & Dsb & Dfb & Dfc \\
\hline Average & 1.76 & 0.23 & 1.6 & 0.96 & 0.20 & 1.02 & 0.78 & 0.17 & 0.01 \\
Spread & 3.33 & 0.44 & 1.36 & 0.72 & 0.60 & 0.70 & - & 0.47 & 0.03 \\
\hline
\end{tabular}

The winter seasonal cost savings have been determined country by country, since the prices for natural gas depend on the national energy market. Applying strategy A, the lowest beneficiary of $S H R$ is found for Greece as a state $(3.57 \mathrm{EUR} /(1 / \mathrm{s}))$, while Messina is still the least convenient $(2.68 \mathrm{EUR} /(1 / \mathrm{s}))$ city. Sweden shows the highest average saving especially in Kiruna with $(22.99 \mathrm{EUR} /(1 / \mathrm{s}))$. The impact of increasing $S L L$ on the cost savings is in line with 
the reduction of the energy savings. The cost savings of Portugal, the Netherlands, and the United Kingdom are the most affected by applying the control strategy B with a reduction of 3.30, 2.74, and $2.28 \mathrm{EUR} /(\mathrm{l} / \mathrm{s})$ for a $S L L$ of $1.6 \mathrm{~g}_{\mathrm{v}} / \mathrm{kg}_{\mathrm{da}}$. In summer mode, the largest cost savings are for Greece, Spain, Italy, Portugal, and France, respectively, with $0.37 \pm 0.11,0.34 \pm 0.31,0.28 \pm 0.11,0.18 \pm 0.12$, and $0.10 \pm 0.07 \mathrm{EUR} /(\mathrm{l} / \mathrm{s})$. For Germany, Finland, Norway, the Netherlands, Poland, Sweden, and the UK the cost savings amount to less than $0.10 \mathrm{EUR} /(1 / \mathrm{s})$.

Annual total cost savings (i.e., the sum of the winter and summer mode cost savings) have been represented in Figure 7: as can be seen, the impact of savings in summer mode are negligible with respect to savings in winter mode.

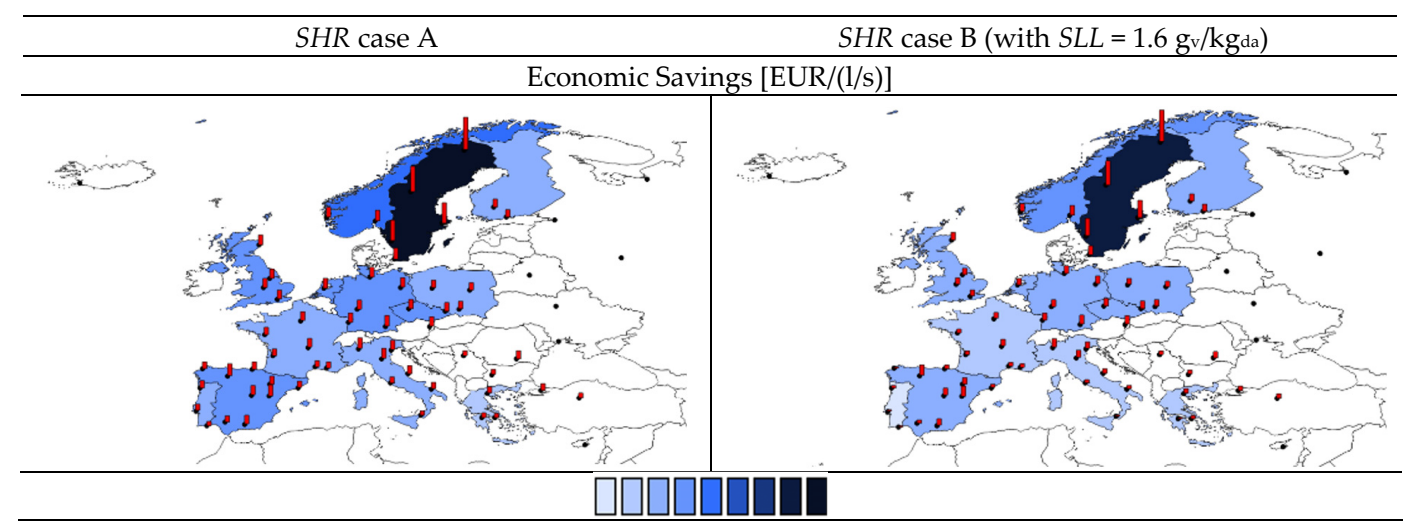

Figure 7. Total cost savings by case A (left) and case B (right) with $S L L=1.6 \mathrm{~g}_{\mathrm{v}} / \mathrm{kg}_{\mathrm{da}}$, for $S H R$. The nine-color scale ranges from less than $2 \mathrm{EUR} /(\mathrm{l} / \mathrm{s})$ to more than $16 \mathrm{EUR} /(\mathrm{l} / \mathrm{s})$ in steps of $2 \mathrm{EUR} /(1 / \mathrm{s})$.

Simple payback time and net present value have been calculated for each city and averaged for the country the cities are located in. The simple payback time for SHR, when nominal recovery is considered (case A), is less than 2 months for all countries. Applying the control strategy (i.e., case B) increases the payback time especially for a SLL of $2.4 \mathrm{~g}_{\mathrm{v}} / \mathrm{kg}_{\mathrm{da}}$ for Spain $(0.75 \pm 1.88 \mathrm{a})$ and Portugal $(0.55 \pm 0.05$ a) (Figure 8). The shortest payback time results for Sweden for all control strategies and $S L L$ values, which makes the investment very convenient with a net present value of more than 170 EUR/(1/s). Apart from this outstanding high value, using the SHR under nominal conditions (case A) leads to a maximum present value for Norway of $102.1 \pm 2.6 \mathrm{EUR} /(\mathrm{l} / \mathrm{s})$ and a minimum for Greece of $46.52 \pm 7.5 \mathrm{EUR} /(\mathrm{l} / \mathrm{s})$. Control strategy B for a $S L L$ of $1.6 \mathrm{~g}_{\mathrm{v}} / \mathrm{kg}_{\mathrm{da}}$ reduces these values respectively to $83.6 \pm 10.6 \mathrm{EUR} /(\mathrm{l} / \mathrm{s})$ for Norway and to $43.1 \pm 20.8 \mathrm{EUR} /(\mathrm{l} / \mathrm{s})$ for Greece, while in that case the minimum present value occurs for Portugal with $14.6 \pm 5.6 \mathrm{EUR} /(1 / \mathrm{s})$.

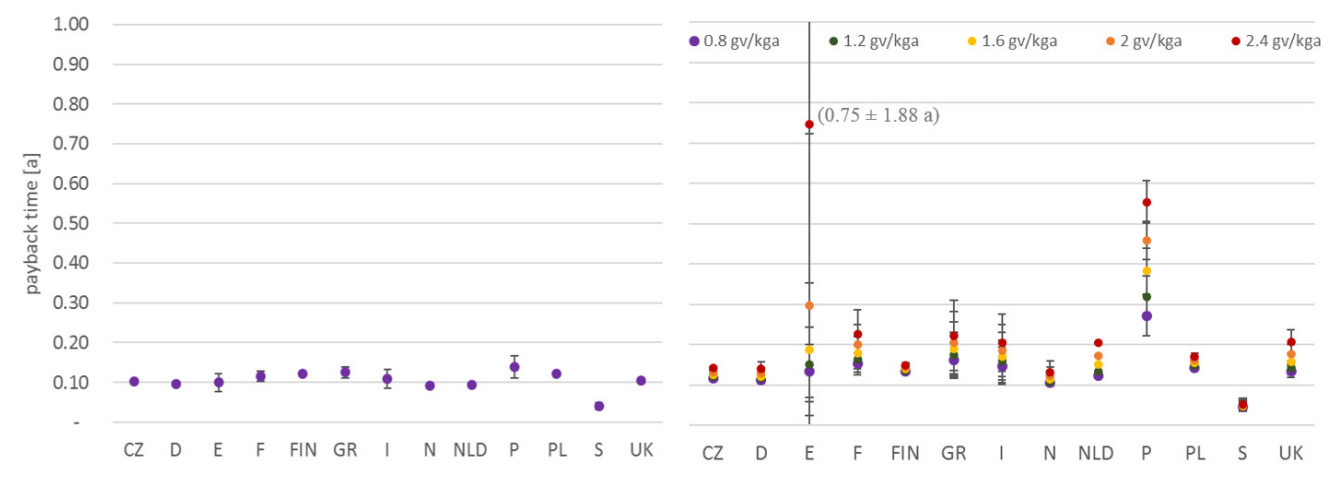

Figure 8. Payback time for the SHR device for control strategy A (left) and B (right). 


\subsection{Total Heat Recovery}

Similarly to the SHR, the nominal savings (control strategy A) with THR are the highest in the coldest climate Dfc and the lowest for Csa (Figure 9). This time, the savings are linked to the indoor humidity, and therefore to the SLL. Considering a $S L L$ of $0.8 \mathrm{~g}_{\mathrm{v}} / \mathrm{kg}_{\mathrm{da}}$, the THR ranges between $53.6 \mathrm{kWh} /(1 / \mathrm{s})$ in Messina and $300.8 \mathrm{kWh} /(1 / \mathrm{s})$ in Kiruna. The highest considered SLL (i.e., $2.4 \mathrm{~g}_{\mathrm{v}} / \mathrm{kg}_{\mathrm{da}}$ ) leads to savings in the range from $104.4 \mathrm{kWh} /(1 / \mathrm{s})$ in Larnaca, Cyprus, to $380.4 \mathrm{kWh} /(1 / \mathrm{s})$ in Kiruna. An average $S L L$ of $1.6 \mathrm{~g} / \mathrm{kg}_{\text {da }}$ leads to an energy reduction of $111.9 \mathrm{kWh} /(\mathrm{l} / \mathrm{s})$ with a spread of $78.2 \mathrm{kWh} /(\mathrm{l} / \mathrm{s})$ for Csa, 153.8 with a spread of $79.1 \mathrm{for} \mathrm{Csb}, 165.1$ with a spread of 45.9 for BSk, 148.1 with a spread of 32.5 for $\mathrm{Cfa}, 193.3$ with a spread of $96.3 \mathrm{for} \mathrm{Cfb}, 176.6$ with a spread of 18.4 for Dfa, 208.4 for Dsb, 223.1 with a spread of 64.1 for Dfb, and 284.7 with a spread of 65.1 for Dfc. The most representative cities are respectively Rome, La Coruna, Madrid, Venice, Frankfurt, Bucharest, Munich, and Arkhangelsk. Similarly, in the case of SHR, the standard deviation is the largest for Csb (i.e., 28\%) and the smallest for Dfa (i.e., 5.2\%).

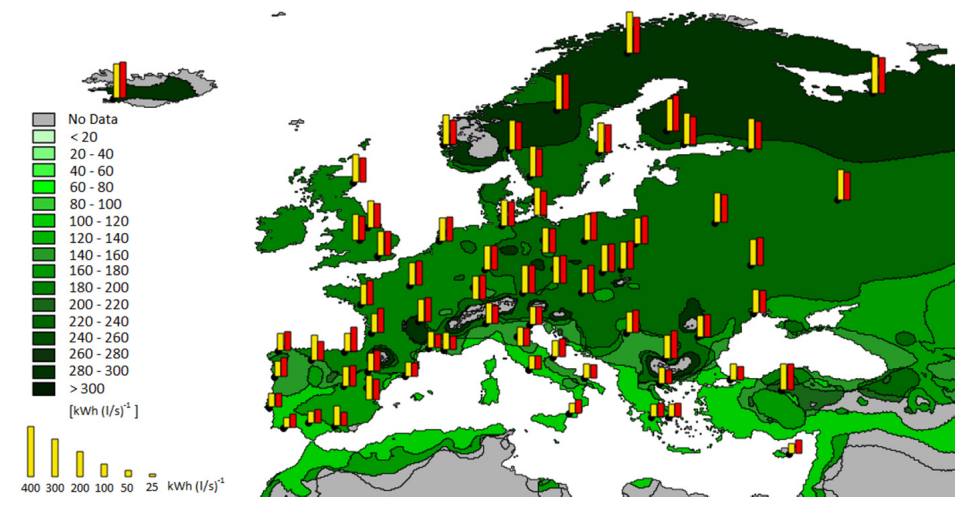

Figure 9. Heating energy savings on the ventilation load for the THR control strategy A and $S L L=1.6 \mathrm{~g}_{\mathrm{v}} / \mathrm{kg}_{\mathrm{da}}$. Colours and red bars indicate the average in the climatic zone. Yellow bar indicates the performance of each locality.

The energy saving potential in winter mode significantly reduces for the control strategy B (Figure 10 and Table 6), with the minimum effect in zone Dfc and the maximum in Csa. In particular, moving from Dfc to Csa, the saving reduces from $10.1 \%$ to $48.4 \%$ for $S L L=0.8 \mathrm{~g}_{\mathrm{v}} / \mathrm{kg}_{\mathrm{da}}$, from $18.8 \%$ to $66.2 \%$ for $S L L=1.2 \mathrm{~g}_{\mathrm{v}} / \mathrm{kg}_{\mathrm{da}}$, from $30.9 \%$ to $78.8 \%$ for $S L L=1.6 \mathrm{~g}_{\mathrm{v}} / \mathrm{kg}_{\mathrm{da}}$, from $44.8 \%$ to $87.1 \%$ for $S L L=2.0 \mathrm{~g}_{\mathrm{v}} / \mathrm{kg}_{\mathrm{da}}$, and from $57.5 \%$ to $92.3 \%$ for $S L L=2.4 \mathrm{~g}_{\mathrm{v}} / \mathrm{kg}_{\mathrm{da}}$. Still, the highest savings occur for Kiruna and the lowest in zones Csa and Csb.

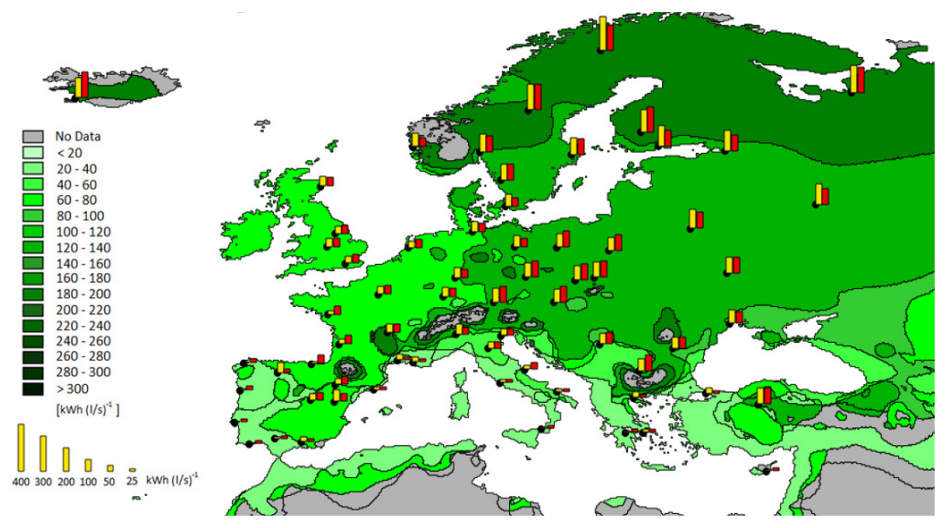

Figure 10. Heating energy savings on the ventilation load for the THR control strategy B and $S L L=1.6 \mathrm{~g}_{\mathrm{v}} / \mathrm{kg}_{\mathrm{da}}$. Colours and red bars indicate the average in the climatic zone. Yellow bar indicates the performance of each locality. 
Table 6. THR savings absolute $[\mathrm{kWh} /(\mathrm{l} / \mathrm{s})]$ and percentage reduction in winter mode with respect to the potential for the control strategy $\mathrm{B}$.

\begin{tabular}{|c|c|c|c|c|c|c|c|c|c|c|}
\hline \multirow{2}{*}{$\begin{array}{l}\text { Climate } \\
\text { Class }\end{array}$} & \multicolumn{2}{|c|}{$0.8 \mathrm{~g}_{\mathrm{v}} / \mathrm{kg}_{\mathrm{da}}$} & \multicolumn{2}{|c|}{$1.2 \mathrm{~g}_{\mathrm{v}} / \mathrm{kg}_{\mathrm{da}}$} & \multicolumn{2}{|c|}{$1.6 \mathrm{~g}_{\mathrm{v}} / \mathrm{kg}_{\mathrm{da}}$} & \multicolumn{2}{|c|}{$2.0 \mathrm{~g}_{\mathrm{v}} / \mathrm{kg}_{\mathrm{da}}$} & \multicolumn{2}{|c|}{$2.4 \mathrm{~g}_{\mathrm{v}} / \mathrm{kg}_{\mathrm{da}}$} \\
\hline & $\Delta$ & $\Delta \%$ & $\Delta$ & $\Delta \%$ & $\Delta$ & $\Delta \%$ & $\Delta$ & $\Delta \%$ & $\Delta$ & $\Delta \%$ \\
\hline Csa & -38.9 & $48.4 \%$ & 63.1 & $-66.2 \%$ & -88.2 & $-78.8 \%$ & -112.2 & $-87.1 \%$ & -134.5 & $-92.3 \%$ \\
\hline Csb & 1.5 & 46.2 & 4.4 & $\%$ & -119.8 & $-77.9 \%$ & -152.5 & -8 & 3.2 & $-92.0 \%$ \\
\hline BSk & -29.2 & $-23.4 \%$ & -61.2 & $-43.1 \%$ & -102.8 & $-62.3 \%$ & -143.1 & $-75.8 \%$ & -180.7 & $-85.0 \%$ \\
\hline Cfa & -35.4 & $-30.7 \%$ & -61 & $-47.1 \%$ & -93.1 & $-62.8 \%$ & -125.6 & $-75.0 \%$ & -156.3 & $-83.7 \%$ \\
\hline $\mathrm{Cfb}$ & -48.7 & $-32.7 \%$ & -85.0 & $-50.3 \%$ & -127.8 & $-66.1 \%$ & -170.1 & $-77.7 \%$ & -209.7 & $-85.8 \%$ \\
\hline Dfa & -27.8 & $-19.1 \%$ & -52.0 & $-32.9 \%$ & -86.4 & $-48.9 \%$ & -124.4 & $-63.0 \%$ & -161.6 & $-73.9 \%$ \\
\hline Dsb & -26.1 & $-15.0 \%$ & -50.6 & $-27.0 \%$ & -87.1 & $-41.8 \%$ & -132.9 & $-56.8 \%$ & -178.3 & $-68.5 \%$ \\
\hline Dfb & -33.5 & $-18.0 \%$ & -60.1 & $-29.8 \%$ & -99.7 & $-44.7 \%$ & -146.0 & $-58.7 \%$ & -192.6 & $-70.0 \%$ \\
\hline Dfc & -25.5 & $-10.1 \%$ & -49.7 & $-18.8 \%$ & -87.8 & $-30.9 \%$ & -139.5 & $-44.8 \%$ & -196.1 & $-57.5 \%$ \\
\hline
\end{tabular}

The average energy savings in summer mode are the largest for zone Csa and the lowest for Dfc and Dsb. In contrast to SHR, for THR a control strategy has also been considered (Table 7). Nevertheless, it must be noted that the savings are calculated on the basis of air condition changed by $H R$ and additional savings expected because of the reduction in dehumidification need are not accounted for.

Table 7. THR average savings in electrical energy demand in summer mode $\left[\mathrm{kWh}_{\mathrm{el}} /(\mathrm{l} / \mathrm{s})\right]$ with or without a control strategy.

\begin{tabular}{cccccccccccccc}
\hline \multirow{2}{*}{$\begin{array}{c}\text { Climate } \\
\text { Class }\end{array}$} & \multicolumn{2}{c}{ No Control } & \multicolumn{3}{c}{ Control-0.8 } & \multicolumn{3}{c}{ Control-1.2 } & \multicolumn{3}{c}{ Control-1.6 } & \multicolumn{3}{c}{ Control-2.0 } & \multicolumn{3}{c}{ Control-2.4 } \\
\cline { 2 - 12 } & Mean & Spread & Mean & Spread & Mean & Spread & Mean & Spread & Mean & Spread & Mean & Spread \\
\hline Csa & 1.91 & 5.25 & 1.89 & 5.24 & 1.89 & 5.24 & 1.90 & 5.25 & 1.90 & 5.25 & 1.90 & 5.25 \\
Csb & 0.05 & 0.15 & 0.05 & 0.15 & 0.05 & 0.15 & 0.05 & 0.15 & 0.05 & 0.15 & 0.05 & 0.15 \\
BSk & 0.23 & 0.42 & 0.20 & 0.35 & 0.20 & 0.36 & 0.21 & 0.38 & 0.22 & 0.40 & 0.22 & 0.40 \\
Cfa & 1.39 & 0.90 & 1.38 & 0.90 & 1.38 & 0.90 & 1.39 & 0.90 & 1.39 & 0.90 & 1.39 & 0.90 \\
Cfb & 0.10 & 0.40 & 0.10 & 0.40 & 0.10 & 0.40 & 0.10 & 0.40 & 0.10 & 0.40 & 0.10 & 0.40 \\
Dfa & 0.62 & 0.49 & 0.61 & 0.48 & 0.61 & 0.48 & 0.62 & 0.49 & 0.62 & 0.49 & 0.62 & 0.49 \\
Dsb & 0.01 & - & 0.01 & - & 0.01 & - & 0.01 & - & 0.01 & - & 0.01 & - \\
Dfb & 0.08 & 0.25 & 0.08 & 0.25 & 0.08 & 0.25 & 0.08 & 0.25 & 0.08 & 0.25 & 0.08 & 0.25 \\
Dfc & 0.01 & 0.06 & 0.01 & 0.06 & 0.01 & 0.06 & 0.01 & 0.06 & 0.01 & 0.06 & 0.01 & 0.06 \\
\hline
\end{tabular}

The cost savings in winter mode by applying control strategy A are the highest for Sweden, especially for Kiruna (38.18 EUR/(1/s)), and the lowest for Greece as a state and for Belgrade in Serbia as a city $(6.70 \mathrm{EUR} /(1 / \mathrm{s}))$, for $S L L=1.6 \mathrm{~g}_{\mathrm{v}} / \mathrm{kg}_{\mathrm{da}}$. A rising $S L L$ increases the savings but the opposite behavior occurs if the control strategy B is applied. Using control B, THR provides the highest cost saving for Sweden and the lowest for Portugal. Regarding summer mode, without control the cost savings are large for Italy, Greece, Portugal, and Spain, with $0.50 \pm 0.31,0.26 \pm 0.08,0.17 \pm 0.12$, and $0.12 \pm 0.19 \mathrm{EUR} /(\mathrm{l} / \mathrm{s})$, respectively. Every other country has average national cost savings lower than $0.10 \mathrm{EUR} /(1 / \mathrm{s})$. In line with the energy savings by THR using the control strategy, changes to cost savings are negligible.

Annual total cost savings (i.e., the sum of the winter and summer mode cost savings) have been represented in Figure 11: as can be seen, the impact of savings in summer mode is negligible with respect to savings in winter mode.

The annual cost savings for the control strategy A lead to a simple payback time for the THR device for all considered SLLs and all countries that is lower than 5 months. The impact of the effectiveness control by strategy B is shown in Figure 12. Again, the device's payback time is the lowest in Sweden with less than a month for all SLLs. In Spain, Portugal, and Greece the payback time is the highest. The various climatic conditions of the considered cities in Spain cause (especially for a SLL of $2.4 \mathrm{~g}_{\mathrm{v}} / \mathrm{kg}_{\mathrm{da}}$ ) an extremely high payback time of $27.2 \mathrm{a}$ and standard deviation $76.1 \mathrm{a}$. 
The net present value for THR with control strategy A is the highest for Sweden from $329.4 \pm 67.0$ to $457.5 \pm 54.8 \mathrm{EUR} /(1 / \mathrm{s})$ for a $S L L$ from 0.8 to $2.4 \mathrm{~g}_{\mathrm{v}} / \mathrm{kg}_{\mathrm{da}}$. For all other countries, the present value ranges between $74.3 \pm 11.3 \mathrm{EUR} /(\mathrm{l} / \mathrm{s})$ for a $S L L$ of $0.8 \mathrm{~g}_{\mathrm{v}} / \mathrm{kg}_{\mathrm{da}}$ (Greece) and $244.9 \pm 4.5 \mathrm{EUR} /(\mathrm{l} / \mathrm{s})$ (Norway) for a $S L L$ of $2.4 \mathrm{~g}_{\mathrm{v}} / \mathrm{kg}_{\mathrm{da}}$. The investment becomes less attractive if control B is applied, especially for Portugal and Greece, respectively $10.5 \pm 4.6$ and $25.1 \pm 13.2 \mathrm{EUR} /(1 / \mathrm{s})$ for a SLL of $1.6 \mathrm{~g}_{\mathrm{v}} / \mathrm{kg}_{\mathrm{da}}$. Excluding Sweden $(175.5 \pm 81.2-288.1 \pm 82.9 \mathrm{EUR} /(\mathrm{l} / \mathrm{s}))$ which is far from the other countries, generally the range for control B is within $3.8 \pm 1.9$ and $130.4 \pm 17.9 \mathrm{EUR} /(1 / \mathrm{s})$, respectively, for Portugal and Norway for SLL from 2.4 to $0.8 \mathrm{~g}_{\mathrm{v}} / \mathrm{kg}_{\mathrm{da}}$.

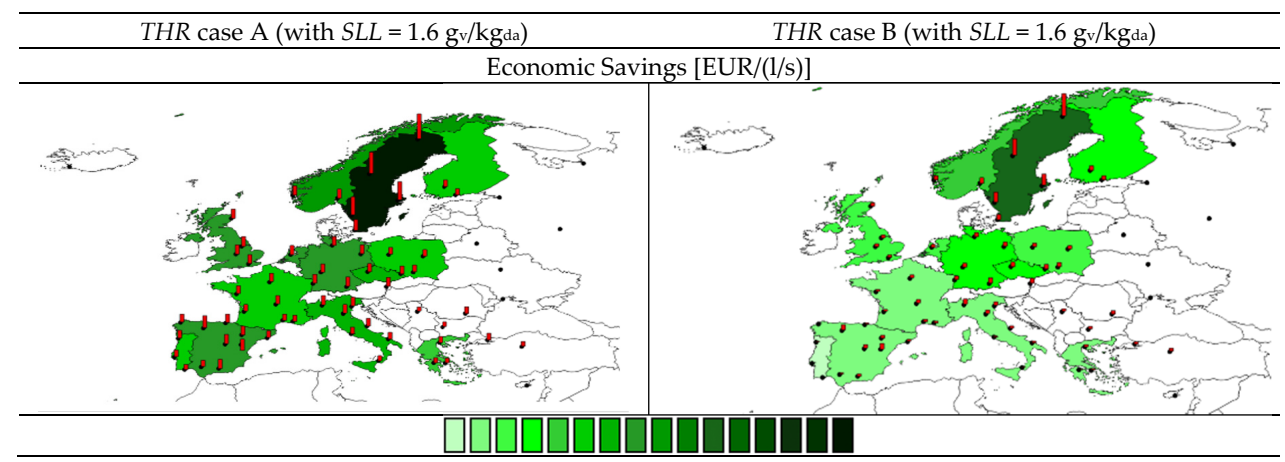

Figure 11. Total cost savings by case A (left) and case B (right) with $S L L=1.6 \mathrm{~g}_{\mathrm{v}} / \mathrm{kg}_{\mathrm{da}}$, for $T H R$. The 16-color scale ranges from less than $2 \mathrm{EUR} /(1 / \mathrm{s})$ to more than $30 \mathrm{EUR} /(1 / \mathrm{s})$ in steps of $2 \mathrm{EUR} /(1 / \mathrm{s})$.

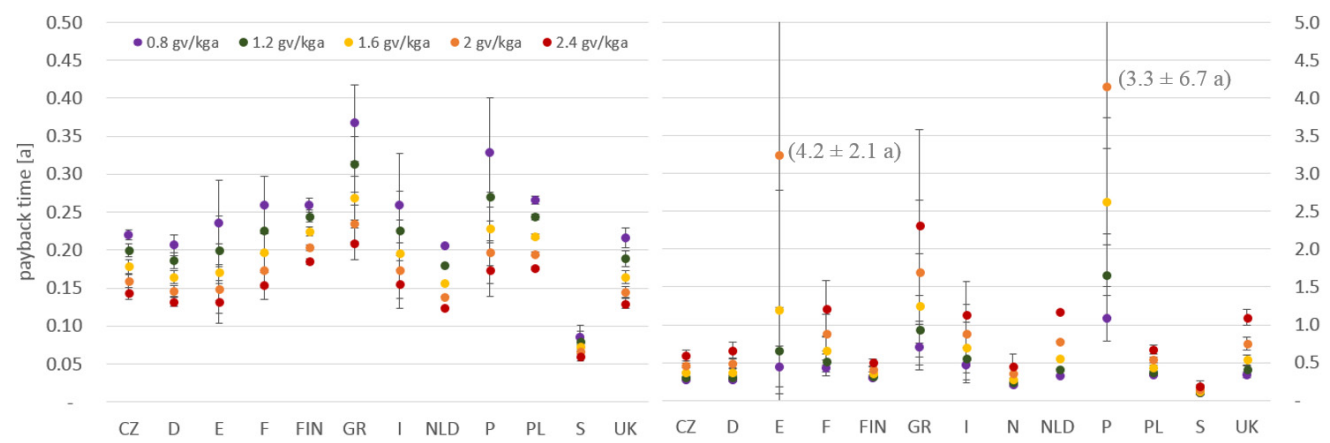

Figure 12. Payback time for the THR device for control strategy A (left) and B (right). Maximum payback times are not visible for $S L L 2.4 \mathrm{~g}_{\mathrm{v}} / \mathrm{kg}_{\mathrm{da}}$ for Spain $(27.0 \pm 76.2 \mathrm{a})$ and Portugal $(6.1 \pm 2.8 \mathrm{a})$.

\subsection{Applicational Aspects Influencing the Energy Savings}

Decisions in the choice and operation of the $H R$ device can influence the potential of the energy savings. In this paragraph, effectiveness, operation period, and frost protection strategies have been analyzed more in detail for the case $S L L=1.6 \mathrm{~g}_{\mathrm{v}} / \mathrm{kg}_{\mathrm{da}}$.

First, the calculations have been also repeated for nominal effectiveness of $60 \%$ and $80 \%$. Figure 13 shows the reduction in the energy savings caused by control strategy B with respect to control strategy A for winter mode and a $S L L$ of $1.6 \mathrm{~g}_{\mathrm{v}} / \mathrm{kg}_{\mathrm{da}}$. For the $S H R$, control strategy B by-passes the HR device for certain air conditions, independent of the effectiveness. For that reason, there is no difference in the savings reduction. On the contrary, the impact of the control strategy B on the energy saving potential by THR is increasing for higher total nominal effectiveness. While for Csa, the decrease is only $13 \%$ passing from a nominal effectiveness of $60 \%$ to $80 \%$, and is $29 \%$ for Dfc, which leads to more than a double-fold reduction of potential energy savings if control strategy B is applied. This trend can be explained by observing that the partialized area, in orange in Figure 3, becomes larger with increasing effectiveness. For the summer mode, variations lower than $1 \%$ have been found. 
The previous results consider the saving potential for a 24-h operation of the mechanical ventilation, in order to not focus on a specific building use and occupation schedule. Nevertheless, since the operation period can influence the energy saving potential, the calculations have been repeated distinguishing daytime (from 6:00 to 18:00) and nighttime periods (from 18:00 to 6:00).

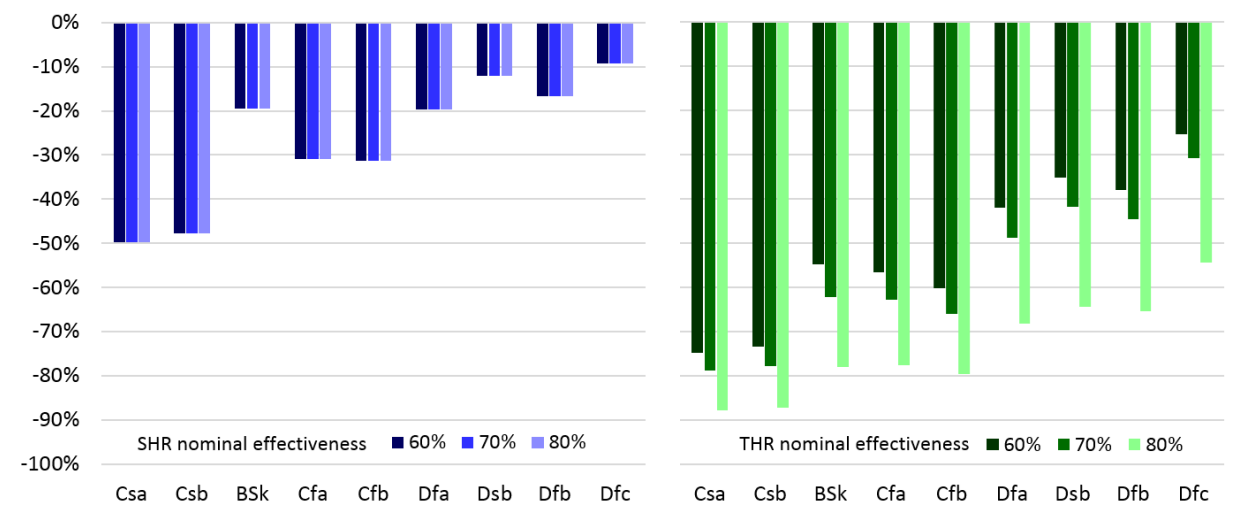

Figure 13. Percentage reduction in winter mode from control strategy A with respect to control strategy B for different nominal effectiveness of $S H R$ and THR for a $S L L$ of $1.6 \mathrm{~g}_{\mathrm{v}} / \mathrm{kg}_{\mathrm{da}}$.

Table 8 shows, for each climate class, the share of energy savings achieved for a SLL of $1.6 \mathrm{~g}_{\mathrm{v}} / \mathrm{kg}_{\mathrm{da}}$ in daytime. In summer mode, for all climate classes, for both SHR and THR the majority of the savings is gained during the daytime: it ranges from $80.3 \%$ (BSk) to $94 \%$ (Dfc) for $S H R$ and from $61.7 \%$ (Cfa) to 94.3\% (Dsb) for THR in both control strategies. In winter mode, the share of daytime energy savings is below half of the total amount for all climate classes and control strategies: the share of daytime energy savings achieved by SHR with control A ranges from $40.9 \%$ (Csa) to $47.7 \%$ (Dfc). Control B shows a weak influence, with the share slightly increasing by a maximum of $2.3 \%$ for Dfa. The daytime share with THR is similar as that for SHR and ranges from $43.5 \%$ (Dsb) to $48.4 \%$ (Dfc). Also in that case, the difference in the energy savings during the daytime period is very close for control A and B, with a maximum increase of $2.8 \%$ for BSk.

Table 8. Percentage of energy savings by $S H R$ and THR during the daytime period considering control $\mathrm{A}$ and $\mathrm{B}$ and $\mathrm{a} L L$ of $1.6 \mathrm{~g}_{\mathrm{v}} / \mathrm{kg}_{\mathrm{da}}$.

\begin{tabular}{cccccccc}
\hline \multirow{2}{*}{$\begin{array}{c}\text { Climate } \\
\text { Class }\end{array}$} & \multicolumn{3}{c}{ SHR } & \multicolumn{3}{c}{ THR } \\
\cline { 2 - 7 } & Summer Mode & \multicolumn{2}{c}{ Winter Mode } & \multicolumn{2}{c}{ Summer Mode } & \multicolumn{2}{c}{ Winter Mode } \\
\cline { 2 - 7 } & Control A & Control A & Control B & Control A & Control B & Control A & Control B \\
\hline Csa & $83.4 \%$ & $40.9 \%$ & $43.1 \%$ & $63.1 \%$ & $63.1 \%$ & $44.2 \%$ & $45.3 \%$ \\
Csb & $92.5 \%$ & $43.2 \%$ & $43.7 \%$ & $86.6 \%$ & $86.5 \%$ & $45.5 \%$ & $45.7 \%$ \\
BSk & $80.3 \%$ & $43.0 \%$ & $44.3 \%$ & $75.0 \%$ & $76.0 \%$ & $45.3 \%$ & $48.1 \%$ \\
Cfa & $85.1 \%$ & $42.7 \%$ & $44.3 \%$ & $61.7 \%$ & $61.7 \%$ & $45.2 \%$ & $45.8 \%$ \\
Cfb & $88.1 \%$ & $44.5 \%$ & $45.8 \%$ & $75.1 \%$ & $75.1 \%$ & $46.2 \%$ & $46.7 \%$ \\
Dfa & $89.6 \%$ & $44.3 \%$ & $46.6 \%$ & $71.9 \%$ & $71.8 \%$ & $45.9 \%$ & $47.5 \%$ \\
Dsb & $93.3 \%$ & $42.0 \%$ & $43.4 \%$ & $94.3 \%$ & $94.1 \%$ & $43.5 \%$ & $44.9 \%$ \\
Dfb & $93.5 \%$ & $45.5 \%$ & $47.0 \%$ & $75.8 \%$ & $75.7 \%$ & $46.7 \%$ & $48.1 \%$ \\
Dfc & $94.0 \%$ & $47.7 \%$ & $48.1 \%$ & $76.7 \%$ & $76.7 \%$ & $48.4 \%$ & $48.7 \%$ \\
\hline
\end{tabular}

The total annual savings may be reduced if a frost protection is implemented. Again, as the impact strongly depends on the type of device and application, only a general example is given. Specifically, it has been considered as a pre-heating system before the $H R$ device with a threshold temperature of $-1{ }^{\circ} \mathrm{C}$ for $S H R$ and $-6{ }^{\circ} \mathrm{C}$ for THR, as in [10].

Table 9 lists all those cities for which the energy savings, achieved by SHR under control A, are reduced by more than $5 \%$ because of the considered frost protection. The highest influence is seen for Arkhangelsk and Kiruna, both located in Dfc. The absolute value of the reduction is not affected by 
the $S H R$ control strategy for a $S L L$ of $1.6 \mathrm{~g}_{\mathrm{v}} / \mathrm{kg}_{\mathrm{da}}$ but, considering that the energy savings in winter mode decrease passing from $\mathrm{A}$ to $\mathrm{B}$, the relative impact is larger for the latter kind of control. For THR, the changes in energy savings due to frost protection are smaller than for $S H R$, because of the lower threshold temperature, but the same trend can be detected passing from A to B.

Table 9. List of all cities with a reduction of energy savings in winter mode by pre-heating is higher than $5 \%$ for $S H R$ under control strategy A and a $S L L$ of $1.6 \mathrm{~g}_{\mathrm{v}} / \mathrm{kg}_{\mathrm{da}}$.

\begin{tabular}{ccccccc}
\hline \multirow{2}{*}{ Climate Class } & \multirow{N}{*}{$\mathbf{N}$} & City & \multicolumn{2}{c}{ SHR } & \multicolumn{2}{c}{ THR } \\
\cline { 4 - 6 } & & & Control A & Control B & Control A & Control B \\
\hline Dfa & 44 & Odessa & $5.1 \%$ & $6.2 \%$ & $0.8 \%$ & $1.4 \%$ \\
Dfb & 39 & Minsk & $8.5 \%$ & $10.0 \%$ & $1.6 \%$ & $2.6 \%$ \\
Dfb & 45 & Oslo & $5.4 \%$ & $6.2 \%$ & $3.7 \%$ & $5.7 \%$ \\
Dfb & 41 & Moscow & $13.6 \%$ & $15.7 \%$ & $1.8 \%$ & $2.8 \%$ \\
Dfb & 55 & Saint Petersburg & $9.7 \%$ & $11.1 \%$ & $0.7 \%$ & $1.2 \%$ \\
Dfb & 58 & Stockholm & $5.2 \%$ & $6.3 \%$ & $0.7 \%$ & $1.2 \%$ \\
Dfb & 27 & Kiev & $5.9 \%$ & $6.9 \%$ & $0.5 \%$ & $1.0 \%$ \\
Dfb & 25 & Helsinki & $7.9 \%$ & $9.0 \%$ & $1.5 \%$ & $2.4 \%$ \\
Dfc & 60 & Tampere & $10.1 \%$ & $11.4 \%$ & $2.2 \%$ & $3.3 \%$ \\
Dfc & 5 & Arkhangelsk & $18.3 \%$ & $20.2 \%$ & $5.8 \%$ & $7.9 \%$ \\
Dfc & 46 & Ostersund & $9.8 \%$ & $10.5 \%$ & $1.9 \%$ & $2.7 \%$ \\
Dfc & 28 & Kiruna & $19.7 \%$ & $20.7 \%$ & $6.3 \%$ & $7.9 \%$ \\
\hline
\end{tabular}

\section{Conclusions}

The presented research has investigated the saving potential by heat recovery in ventilation systems in winter and summer modes. Although the nominal potential is high, in practice, it has to be limited in order to avoid counterproductive effects, such as pre-heating air before dehumidification by cooling (both for sensible and total heat recovery) or excessive humidity recovery (for total heat recovery). Consequently, the heat recovery in ventilation expected from the nominal effectiveness (i.e., control strategy A) can be highly overestimated, especially in the case of total heat recovery. A humidity-based control strategy (i.e., control strategy B) has been defined based only on outdoor air conditions and indoor specific latent load, independently of building characteristics or use. Nominal and actual heat recovery have been calculated for 66 European cities starting from the hourly weather data in their reference years. The resulting energy savings have been averaged and mapped on each European Köppen-Geiger climate class. An economic analysis has been performed and cost savings maps have been drawn for some selected countries.

The energy and economic investigations about the correlation of sensible and total heat recovery to climate and control strategies have led to the findings reported below.

With regards to the energy aspects in winter mode:

- As expected, the transition from the temperate, Mediterranean climates to the cold northern conditions corresponds to a rise of the energy savings, both by sensible and total heat recovery. The largest potential is found for the latter, whose nominal performance can be from two to three times higher for sensible heat recovery.

- Introducing a humidity based control strategy (strategy B), sensible heat recovery is reduced with the increase of indoor specific latent load, from a minimum of $5 \%$ in cold climates to a maximum of $65 \%$ in temperate climates.

- Total heat recovery is more sensitive to the introduction of control strategy B, which can lower the energy savings by $10 \%$ (cold climates) and up to $93 \%$ (warm climates), in relation to the indoor specific latent load. Comparing sensible and total heat recovery, it can be observed that the reduction is up to five times higher for the total heat recovery in climate zone Dfc, where there is the largest potential, but only less than 1.5 times in zone Csa, where the lowest potential is 
registered. In contrast to the sensible heat recovery, for the total one the impact of strategy B is also influenced by the nominal effectiveness of the heat recovery device, in particular for zone Dfc.

- Achievable savings during the daytime period are slightly below half of the total amount for both sensible and total heat recovery and the impact of strategy B on nighttime and daytime distributions is small. Consequently, the presented findings can also be generalized to non-continuous operation controls.

- Frost protection can reduce the energy saving potential but this has a limited effect on the relative performance of the humidity-based control strategy B.

With regards to the energy aspects in summer mode:

- The correlation between climate and energy reduction in summer mode is opposite than that for winter and the savings decrease from the Mediterranean to the Nordic climates. Total heat recovery is more beneficial for temperate rather than for arid climates, where sensible heat recovery with indirect evaporative cooling is more favorable. Regarding the cold climates, savings are often negligible for either total or sensible heat recovery with indirect evaporative cooling.

- In contrast to what was observed for the winter mode, savings in the summer mode are strongly dependent on the period of operation, with the largest savings achievable during the daytime period. Nevertheless, the impact of the control strategy B on time distributions is still minimal.

With regards to economic aspects:

- The cost savings in winter mode significantly exceed the values for summer mode.

- With strategy A, sensible heat recovery devices have a payback time lower than 2 months for all considered countries. Applying strategy B, the payback time significantly extends, especially for Portugal and Spain and for large specific latent loads.

- The payback time of the total heat recovery device is for all countries and specific latent loads less than 5 months, in the case of strategy A. Strategy B causes a strong prolongation, which might even overcome the life span of the device for the largest specific latent load of $2.4 \mathrm{~g}_{\mathrm{v}} / \mathrm{kg}_{\mathrm{da}}$ in Spain. The payback time for the total heat recovery device is around two times longer than for the sensible one in the case of strategy A and more than ten times longer in the case of strategy B.

- Analyzing the net present value, the most convenient investment for all considered cases is in Sweden, with the result for the total heat recovery being twice as high as that for the sensible one. In Norway, the net present value for total heat recovery is even three times higher than that for the sensible one.

- The worst economic performance for sensible heat recovery is in Portugal, for both control strategies. The lowest value for total heat recovery occurs for strategy A in Greece and for strategy $B$ in Portugal.

To summarize, considering no control for preventing excessive humidity (strategy A), the savings always prove that the use of total heat recovery is by far more beneficial than sensible heat recovery, no matter which climate class or country is considered.

In contrast, in locations within the climate classes Csa, Csb, Cfa, and BSk there is a similar energy saving potential between sensible and total heat recovery if humidity control (strategy B) is applied. If from an energy efficiency point of view, the performance of the two systems becomes closer, from an economic point of view, the results are slightly different, depending also on the chosen economic indicator: for example, although the sensible heat recovery achieves less cost savings, the payback time is shorter. For countries within these climate zones, the net present value is higher for total rather than for sensible heat recovery when the specific latent load is up to $1.6 \mathrm{~g}_{\mathrm{v}} / \mathrm{kg}_{\mathrm{da}}$. In the case of higher values of the specific latent load, the opposite is true.

The deployment of total heat recovery with humidity control in locations within the zones Dfc, $\mathrm{Dfb}, \mathrm{Dsb}$, Dfa, and Cfb allows for an energy reduction that is larger than the sensible heat recovery. 
The same holds for the cost savings. The total heat recovery seems a better investment than the sensible heat recovery regarding the net present value, although the payback time is higher. Nevertheless, this behaviour changes for higher specific latent loads, due to the control strategy, and the energy savings of the two kinds of heat recovery nearly align with each other for the largest specific latent loads. In that case, the lower investment costs of sensible heat recovery make it more attractive, such as for the warmer climates.

Analyzing the results on a country basis, in the strategy B, the payback time is always higher for the total rather than sensible heat recovery, while considering the net present value, the performance depends on the specific latent load. For Portugal, the net present value is higher for the total heat recovery only for a specific latent load of $0.8 \mathrm{~g}_{\mathrm{v}} / \mathrm{kg}_{\mathrm{da}}$. For the United Kingdom, the Netherlands, Greece, and Spain, the total heat recovery is more convenient for specific latent loads of 0.8 and $1.2 \mathrm{~g}_{\mathrm{v}} / \mathrm{kg}_{\mathrm{da}}$, and for the Czech Republic, Germany, France, and Italy, this occurs also for $1.6 \mathrm{~g}_{\mathrm{v}} / \mathrm{kg}_{\mathrm{da}}$. In Finland, Norway, and Poland, total recovery is preferable for all specific latent loads except for $2.4 \mathrm{~g}_{\mathrm{v}} / \mathrm{kg}_{\mathrm{da}}$. Finally, Sweden is the only considered country for which the application of total heat recovery with the control strategy B is better than sensible heat recovery for all specific latent loads.

Acknowledgments: This study has been funded by the project "Klimahouse and Energy Production" in the framework of the programmatic-financial agreement with the Autonomous Province of Bozen-Bolzano of Research Capacity Building. The authors would like to also thank Giacomo Pernigotto for helping with the preparation of the GIS maps.

Author Contributions: Stefanie Tafelmeier performed the simulations and analyzed the results, with the contribution of Giovanni Pernigotto. Andrea Gasparella defined the scope and methods of the work and supervised the study. All authors contributed in writing, editing, and structuring the paper.

Conflicts of Interest: The authors declare no conflict of interest.

\section{Nomenclature}

$\begin{array}{lll}\mathrm{m} & \text { mass flow rate } & (\mathrm{kg} / \mathrm{s}) \\ \mathrm{T} & \text { temperature } & \left({ }^{\circ} \mathrm{C}\right) \\ \mathrm{x} & \text { humidity ratio } & \left(\mathrm{kg} / \mathrm{kg}_{\text {da }}\right) \\ \mathrm{h} & \text { enthalpy } & (\mathrm{kJ} / \mathrm{kg}) \\ \mathrm{RH} & \text { relative humidity } & (\%)\end{array}$

\section{Greek letter}

$\varepsilon \quad$ effectiveness

\begin{tabular}{ll}
\multicolumn{2}{l}{ Subscript } \\
avg & average \\
CA & recirculating air \\
da & dry air \\
L & load \\
l & latent \\
MA & mixed air \\
min & minimum \\
OA & outside air \\
R & air after recovery \\
RA & return air \\
SA & supply air \\
s & sensible \\
$\mathrm{t}$ & total \\
V & vapor
\end{tabular}




\section{References}

1. Hwang, R.L.; Lin, T.P.; Kuo, N.J. Field experiments on thermal comfort in campus classrooms in Taiwan. Energy Build. 2006, 38, 53-62. [CrossRef]

2. Kosonen, R.; Tan, F. Assessment of productivity loss in air-conditioned buildings using PMV index. Energy Build. 2004, 36, 987-993. [CrossRef]

3. Tsutsumi, H.; Tanabe, S.I.; Harigaya, J.; Iguchi, Y.; Nakamura, G. Effect of humidity on human comfort and productivity after step changes from warm and humid environment. Build. Environ. 2007, 42, 4034-4042. [CrossRef]

4. Chen, Y.; Tsutsumi, H.; Akimotob, T.; Tanabe, S.; Takagi, T. Subjective experiments on the effects of relative humidity and humidity ratio during summer season. In Proceedings of the ISlAQ 7th International Conference, Singapore, 7-12 December 2003; Wai, T.K., Sekhar, C., Cheong, D., Eds.; pp. 293-298.

5. Sterling, E.M.; Arundel, A.; Sterling, T.D. Criteria for Human Exposure To Humidity in Occupied Buildings. ASHRAE Trans. 1985, 91 pt 1B, 611-622.

6. Smith, K.M.; Svendsen, S. The effect of a rotary heat exchanger in room-based ventilation on indoor humidity in existing apartments in temperate climates. Energy Build. 2016, 116, 349-361. [CrossRef]

7. Lazzarin, R.M.; Gasparella, A. Technical and economical analysis of heat recovery in building ventilation systems. Appl. Therm. Eng. 1998, 18, 47-67. [CrossRef]

8. Zhang, J.; Fung, A.S.; Jhingan, S. Analysis and feasibility study of residential integrated heat and energy recovery ventilator with built-in economizer using an excel spreadsheet program. Energy Build. 2014, 75, 430-438. [CrossRef]

9. Guillén-lambea, S.; Rodríguez-soria, B.; Marín, J.M. Evaluation of the potential energy recovery for ventilation air in dwellings in the South of Europe. Energy Build. 2016, 128, 384-393. [CrossRef]

10. Rafati Nasr, M.; Fauchoux, M.; Besant, R.W.; Simonson, C.J. A review of frosting in air-to-air energy exchangers. Renew. Sustain. Energy Rev. 2014, 30, 538-554. [CrossRef]

11. Zeno, B.; Spiekman, M.; Troi, A. Energy Retrofit of Cultural Heritage Buildings. REHVA J. 2014. Available online: http:/ / www.rehva.eu/publications-and-resources/rehva-journal/2014/032014/energyretrofit-of-cultural-heritage-buildings.html (accessed on 22 March 2017).

12. Lazzarin, R.M.; Gasparella, A.; Longo, G.A.; Perbellini, M. Gli scambia tori di calore aria aria: Potenzialità applicative nella riduzione del carico di ventilazione degli edifici. In Atti Del 55 Congresso Nazionale ATI; Edizioni SGE: Padova, Italy, 2000.

13. International Organization for Standardization. ISO 7730: Ergonomics of the Thermal Environment-Analytical Determination and Interpretation of Thermal Comfort Using Calculation of the PMV and PPD Indices and Local Thermal Comfort Criteria; International Organization for Standardization: Geneva, Switzerland, 2005.

14. Ente Italiano di Normazione. In UNI 10339: impianti aeraulici al fini di benessere. Generalità, classificazione e requisiti. Regole per la richiesta d'offerta, l'offerta, l'ordine e la fornitura; Ente Italiano di Normazione: Milan, Italy, 1994.

15. Gasparella, A.; Longo, G.A. Indirect evaporative cooling and economy cycle in summer air conditioning. Int. J. Energy Res. 2003, 27, 625-637. [CrossRef]

16. EnergyPlus. Available online: https:/ / energyplus.net/weather (accessed on 10 December 2016).

17. Peel, M.C.; Finlayson, B.L.; McMahon, T.A. Updated world map of the Köppen-Geiger climate classification. Meteorol. Z. 2006, 15, 259-263.

18. Kontonasiou, E.; Mariottini, F.; Atanasiu, B. Indoor Air Quality, Thermal Comfort and Daylight; Buildings Performance Institute Europe (BPIE): Brussels, Belgium, 2015.

19. Deshko, V.I.; Ya, A.; Sukhodub, I.O. Heat and mass transfer in cross-flow air-to-air membrane heat exchanger in heating mode. Appl. Therm. Eng. 2016, 100, 133-145. [CrossRef]

20. Simonson, C.J.; Besant, R.W. Heat and Moisture Transfer in Energy Wheels During Sorption, Condensation, and Frosting Conditions. ASME J. Heat Transfer 1998, 120, 699-708. [CrossRef]

21. Holmberg, R.B. Sensible and Latent Heat Transfer in Cross-Counterflow Gas-To-Gas Heat Exchangers. ASME J. Heat Transfer 1989, 111, 173-177. [CrossRef]

22. Anisimov, S.; Jedlikowski, A.; Pandelidis, D. Frost formation in the cross-flow plate heat exchanger for energy recovery. Int. J. Heat Mass Transf. 2015, 90, 201-217. [CrossRef] 
23. Tafelmeier, S.; Longo, G.A.; Gasparella, A. Energy and Economic Performance Analysis of Heat Recovery Devices Under Different Climate Conditions. In Proceedings of the International High Performance Buildings Conference, Purdue University, West Lafayette, IN, USA, 11-14 July 2016.

24. Nam, S.H.; Han, H. Computational modeling and experimental validation of heat recovery ventilator under partially wet conditions. Appl. Therm. Eng. 2016, 95, 229-235. [CrossRef]

25. Eurostat. Available online: http:/ / ec.europa.eu/eurostat/about/overview (accessed on 30 November 2016).

26. Comune di Milano. Listino prezzi per l'esecuzione di opere pubbliche e manutenzioni; Comune di Milano: Milano, Italy, 2015.

27. European Commission. EU Commission Delegated Regulation 244/2012, Energy Performance of Buildings-Economic Evaluation Procedure for Energy Systems in Buildings; European Commission: Brussels, Belgium, 2012.

28. StatisticsFinland. Available online: http://www.stat.fi/til/ehi/2015/04/ehi_2015_04_2016-03-09_tau_002_ en.html (accessed on 30 November 2016).

29. Gasnor, AS. Available online:. Available online: http://gasnor.no/bolig/priserbetingelser/ (accessed on 19 December 2016).

(c) 2017 by the authors. Licensee MDPI, Basel, Switzerland. This article is an open access article distributed under the terms and conditions of the Creative Commons Attribution (CC BY) license (http:/ / creativecommons.org/licenses/by/4.0/). 